\title{
Assessing learning and memory in pigs
}

\author{
Elise Titia Gieling • Rebecca Elizabeth Nordquist • \\ Franz Josef van der Staay
}

Received: 10 May 2010/Revised: 23 November 2010/Accepted: 25 November 2010/Published online: 4 January 2011

(C) The Author(s) 2010. This article is published with open access at Springerlink.com

\begin{abstract}
In recent years, there has been a surge of interest in (mini) pigs (Sus scrofa) as species for cognitive research. A major reason for this is their physiological and anatomical similarity with humans. For example, pigs possess a welldeveloped, large brain. Assessment of the learning and memory functions of pigs is not only relevant to human research but also to animal welfare, given the nature of current farming practices and the demands they make on animal health and behavior. In this article, we review studies of pig cognition, focusing on the underlying processes and mechanisms, with a view to identifying. Our goal is to aid the selection of appropriate cognitive tasks for research into pig cognition. To this end, we formulated several basic criteria for pig cognition tests and then applied these criteria and knowledge about pig-specific sensorimotor abilities and behavior to evaluate the merits, drawbacks, and limitations of the different types of tests used to date. While behavioral studies using (mini) pigs have shown that this species can perform learning and memory tasks, and much has been learned about pig cognition, results have not been replicated or proven replicable because of the lack of validated,
\end{abstract}

E. T. Gieling $(\varangle) \cdot$ R. E. Nordquist · F. J. van der Staay

Faculty of Veterinary Medicine,

Department of Farm Animal Health,

Emotion and Cognition Program, Utrecht University,

Yalelaan 7, 3584 CL Utrecht, The Netherlands

e-mail: e.t.gieling@uu.nl

R. E. Nordquist

e-mail: r.e.nordquist1@uu.nl

F. J. van der Staay

e-mail: f.j.vanderstaay@uu.nl

E. T. Gieling - R. E. Nordquist - F. J. van der Staay

Rudolf Magnus Institute of Neuroscience,

Universiteitsweg 100, Utrecht, The Netherlands translational behavioral paradigms that are specially suited to tap specific aspects of pig cognition. We identified several promising types of tasks for use in studies of pig cognition, such as versatile spatial free-choice type tasks that allow the simultaneous measurement of several behavioral domains. The use of appropriate tasks will facilitate the collection of reliable and valid data on pig cognition.

Keywords Pig - Cognition · Learning - Memory · Welfare $\cdot$ Model animal

\section{Introduction}

Over the past 100 years, scientists have shown that a number of animal species have substantial cognitive (i.e., learning and memory) abilities (Broom and Zanella 2004). In recent decades, scientists have primarily focused on rodents and, to a lesser degree, on primates, species considered relevant to human research (van der Staay 2006). When assessing the utility of animal models for investigating cognitive functions such as learning and memory, it is necessary to evaluate which species and what tests are most suitable, produce valid results, and allow generalization to humans (referred to as translational research; Markou et al. 2009).

In general, learning and memory are considered to require higher brain functions and are not merely the acquisition of a series of elicited responses (Kirsch et al. 2004). This is why it is so important to select the correct parameters so that learning is measured rather than more effortless or less deliberate types of performance (for which other strategies are adopted) (Kratzer 1971). Pigs are cooperative animals and learn classical and operant conditioning tasks rapidly (Baldwin 1969; Baldwin and 
Stephens 1973; Chaput et al. 1973; Kratzer 1971). They are generally seen as being 'intelligent' by the public, probably because they can be trained. For example, Breland and Breland (1915) successfully trained pigs for some pig shows, based on B.F. Skinners' operant conditioning methods. Yet despite the growing literature on the cognitive abilities of pigs (including miniature or minipigs) (Ferguson et al. 2009), experience with and knowledge of this species as an animal model are still limited (Hagl et al. 2005). Pigs and minipigs have several advantageous characteristics, such as greater similarity to humans than rodents have, which might favor their use instead of-or alongside - other model species. For this reason, experimental data produced over the past 40 years should be verified and steps taken to advance research in the field of pig cognition. Animal welfare scientists, while sharing the opinion that pigs have considerable cognitive abilities, look at cognitive research in pigs from a different point of view from that of biomedical researchers. Their aim of studying this species is to become more aware of pigs' cognitive abilities and sensory capacities, ultimately to improve the welfare of this intensively kept farm animal (Meehan and Mench 2007; Toates 2004). An additional aspect is that the public's perception of the intelligence of an animal influences the importance attached to its welfare, and many people (consumers) consider farming practices that result in poor animal welfare to be unacceptable (Broom 2010). Cognitive ability should also be considered when designing methods of enriching the environments of captive animals.

The aim of this paper is to review the literature on studies of learning and memory in pigs from these two perspectives, focusing on the different types of tasks used (operant, spatial and recognition tasks, and tasks that assess observational learning and awareness) and distinguishing between appetitively and aversively motivated tasks. We also review the conditions under which tests should be performed in the future.

The pig as model species in biobehavioral research

Although the scientific advantages of using the pig, in particular the minipig, as animal model in biomedical research have long been recognized (e.g. Baldwin and Stephens 1973; Chaput et al. 1973), there has been a recent revival of interest in the pig as model of human disease. The pig has the potential to fill the gap between preclinical studies with rodents and clinical trials in humans (de Groot et al. 2005; Lind et al. 2007; Nunoya et al. 2007; Vodička et al. 2005). Its organ size, body mass, and physiology strongly resemble those of humans (Sachs 1994; Schook et al. 2005), and the immune system of pigs is more similar to that of humans than it is to the immune system of rodents $(80 \%$ similarity of the compared variables between pigs and humans versus $10 \%$ between mice and humans) (Schook et al. 2005). Unlike rodents, which have a lisencephalic brain, pigs have a gyrencephalic brain, as do humans.

The brain of an average adult pig weighs up to $180 \mathrm{~g}$ and that of minipigs 70-80 g (Hofman 1985). The relatively large brain of pigs makes it suitable for imaging studies, particularly in young animals (Arnfred et al. 2004; Danielsen et al. 2001). For example, positron emission tomography (PET) studies have investigated aromatic amino acid decarboxylase activity in the brain of newborn piglets (Bauer et al. 2002), magnetic resonance imaging (MRI) has been used to study the temporal expansion following cerebral contusion (Zhang et al. 2008), and functional magnetic resonance imaging (fMRI) has been used to study activity in the cortex, cerebellum, and brainstem following visual stimulation in postnatal piglets (Fang et al. 2006). In addition, the sequence and chromosome structure homology of the pig genome show strong similarity with those of the human genome (Chen et al. 2007; Lunney 2007; Petersen et al. 2008). However, the full potential of pig-based models for investigating the function/dysfunction of the nervous system in the regulation of normal and abnormal behavior has not yet been fully explored (Nielsen et al. 2009; Schook et al. 2005). Overall, it could be said that the pig shows several favorable physical characteristics, including suitability for advanced imaging techniques that support its use in research into human disease (Lind et al. 2007).

Traditionally, behavioral studies have used rodents because of the availability of numerous well-validated tests and models (Kornum et al. 2007), and the ease and cheaper costs of housing rodents compared with larger species. However, the pig may be a good non-primate, non-rodent species for biomedical research, for studying the effects of a wide range of clinical and behavioral stresses (Chaput et al. 1973), for screening in vivo receptor profiles of drugs (Lind et al. 2004), and for verifying neurological syndromes (e.g. MPTP-induced Parkinsonism syndrome; Mikkelsen et al. 1999). Pig models have been used to address lifestyle factors (e.g., stress, drugs, and abuse; Schook et al. 2005), diabetes (Larsen and Rolin 2004), and human brain disorders (Moustgaard et al. 2005; Nielsen et al. 2009).

Another important consideration is that pigs are relatively inexpensive compared with primates (Mikkelsen et al. 1999). Several domestic pig lines and a smaller number of minipig breeds are now commercially available from specialized breeders (e.g., Ellegaard Göttingen Minipig $^{\circledR}$, Yucatan minipig, pot-bellied pig). The minipig is especially suited for behavioral research because of its smaller size, which makes handling easier and allows the scaling down of test equipment, compared with that used 
for the common domestic pig. However, the housing, physiology, and behavior of domestic pigs and minipigs have not yet been directly compared. The nature of the domestic pig and minipig breeding programs is different, especially with regard to weight gain. The Göttingen Minipig is bred to be a small and light laboratory animal (mature animals weigh around $30-35 \mathrm{~kg}$, if they have been put on a calorie-controlled diet) and shows nearly linear growth in the first 160 days of life. In contrast, fattening pigs (weighing 117-138 kg when 26 weeks old, depending on their feeding regime) gain little weight during the first 7 weeks, but thereafter gain weight rapidly (Köhn et al. 2007). Researchers should be aware of these and other differences between the two types of pig when comparing data. Indeed, further research on potential differences is urgently needed.

\section{Learning and memory in relation to welfare}

Greater insight into pig cognition is needed not only with regard to biomedical research, but also with regard to improving pig welfare. Both research lines will benefit from the development of reliable and validated tests for studying pigs' cognitive abilities. Indeed, Duncan and Petherick (1991) stated "animal welfare is dependent solely on the mental, psychological and cognitive needs of the animals concerned". Farm animals, including pigs, are inadvertently exposed to many learning and memory challenges (Held et al. 2002), and knowledge of speciesspecific learning abilities and environmental preferences is expected to contribute to improvement of housing conditions, management, and handling routines, and hence animal welfare (Baldwin and Meese 1977; Boissy et al. 2007; Tanida and Nagano 1998; van Rooijen 1982; Wechsler and Lea 2007). Situations that adversely affect farm animal cognition can trigger stress responses (possibly associated with suffering) and can negatively affect productivity (Held et al. 2002). The capacity of an animal to cope with its housing conditions may be influenced by its learning abilities (Wechsler and Lea 2007).

A range of cognitive factors appear to influence emotions or emotional processes in animals (a topic nowadays of great importance when assessing animal welfare) (Ohl et al. 2008). More complex emotions are the result of interactions between cognitive and emotional processes that are needed for the evaluation of perceptual information (Ohl et al. 2008; Paul et al. 2005). Vice versa, the emotional state of an animal can also influence its cognitive functioning, "judgment of stimuli" (Mendl et al. 2009). Consequently, questions about farm animal welfare cannot be tackled without a thorough understanding of the fundamental psychology and behavior of these animals (Curtis and Stricklin 1991), an aspect that has long been neglected in farm animals (Puppe et al. 2007), but which influences our attitude to these animals. Nowadays, there is a growing public interest in and discussion of animal welfare issues, and cognitive research in farm animals may provide information relevant to these discussions (Mendl and Paul 2004).

Our aim is to review the biomedical and animal welfare literature with a view to facilitating the selection or design of appropriate tasks for pig cognition research. We hope it will prompt collaboration between scientists in both fields, to improve biomedical research models and animal welfare.

Implementation of cognitive tasks

Research into the effects of experimental interventions on cognitive processes in pigs necessitates the development of reliable and valid learning and memory tests (e.g., van der Staay 2006). One of the reasons why pig studies are under-represented in biomedical behavioral research is the lack of well-standardized and validated tasks. A main task of behavioral scientists is to develop or adapt existing tests to generate valid and sensitive test paradigms applicable to most commonly used model animals in addition to pigs and/or suitable for behavioral characterization (phenotyping).

Behavioral tasks for pigs should in general fulfill a number of criteria:

1. healthy, unimpaired animals should be able to acquire/ perform the task;

2. the task should allow a detailed analysis of pigs' behavior, i.e., it should preferentially provide indices for different behavioral domains (cognitive, sensory, motor, or motivational components) (Wainwright and Colombo 2006);

3. the task should be as stress-free as possible (for both the experimental animal and the experimenter; except if measuring the effects of stress is an explicit aim of the experimental procedure);

4. the task should preferentially tap ecologically relevant behaviors (e.g., to prevent mismatches between the task and the adaptive mechanisms and available behavioral repertoire of the species) (Koolhaas et al. 2006);

5. the task should be standardized in order to enable comparisons between studies within and across laboratories (van der Staay et al. 2010);

6. the task should, wherever possible, be automated in order to eliminate variability between observers, and to allow fine-tuned analyses;

7. the task should allow investigation of developmental effects (early ontogeny, aging) and should preferentially 
be suited for repeated testing (van der Staay 2002) in order to allow longitudinal studies;

8. the task should be complex and sensitive enough to capture subtle differences in cognitive abilities (Friess et al. 2007; Hagl et al. 2005; Laughlin et al. 1999).

The above criteria are general criteria for test paradigms. Clearly, some criteria will be more relevant than others, depending on the specific research questions (biomedical or welfare related) and hypotheses tested. A multi-layered approach is needed to cover the full range of pig behavior, because cognition is not a unitary function but involves multiple and dissociable systems that interact in cognitive processes. This should be kept in mind when designing and interpreting studies of cognitive functioning (Wainwright and Colombo 2006).

\section{Species-specific opportunities and constraints}

Pigs are clearly different from rodents. It is important to take the species-specific abilities and constraints into account when developing new tasks or applying existing ones for pigs. In this context, we will briefly discuss the general characteristics of the domestic pig from an evolutionary point of view and give an overview of pigs' known sensory capacities.

\section{General features of the domestic pig}

The behavioral traits of domestic pigs, which were domesticated around 9,000 years ago (Hemmer 1990), closely resemble those of its ancestor, the wild boar (Sus scrofa). Thus, study of wild and/or feral pigs provides insights into the behavior of the domestic pig (Graves 1984). Ethological studies have shown that wild boars, which are highly social and omnivorous (Graves 1984; Gustafsson et al. 1999), concentrate their daily activity into several main periods, generally synchronized with sunrise and sunset (Mauget 1984), depending on season, predator pressure, and food availability. Wild boars are active for about $65 \%$ of the time (Graves 1984), and although mainly diurnal, they can easily shift to nocturnal activity (Jensen 2003). During foraging, they move between different feeding areas while grazing, browsing, or, more commonly, rooting with their snout. Their muzzle (a flattened, tough, rounded disk) searches for food on and under the surface, and pigs generally move with their nostrils close to the ground (Graves 1984). Because pigs lack sweat glands, wallowing in mud or water is a common behavior to decrease body temperature (Jensen 2003).

The natural behavior of feral pigs and their ancestors gives us some insights into behaviors and aspects of domestic pigs that are of significant importance (e.g., rooting, social companionship, and the lack of sweat glands) to their well-being and which should be taken into account when housing experimental animals and designing or selecting suitable tasks. Typical behavior such as rooting could be used as stimulant to motivate animals to perform a task, in addition to food reward. Because most tasks are performed by individual animals, it is essential to habituate these social animals to being alone in the test environment. Fear, stress, or arousal can influence performance and decrease motivation (this will be discussed later on). Keeping the pen mates of the tested individual close to the experimental set-up could help to decrease arousal, because pen mates are within hearing and smelling range of the test pig. In cognitive tests in which the pig's emotional state plays a role, communication and/or pheromone signaling between the test pig and the waiting pen mates may influence test performance. Moreover, it is conceivable that the testing order affects physiological and possibly behavioral measures (e.g. within-cage order effects of testing are found in mice (Arndt et al. 2009)).

\section{Sensory capacities}

\section{Visual and olfactory capacities}

Knowledge about the visual and olfactory capacities of the pig is limited, and the available results are contradictory. Pigs can learn olfactory discrimination tasks faster than visual discrimination tasks (Croney et al. 2003; Lind et al. 2007). However, despite large variations between individual pigs, Tanida and Nagano (1998) found visual as well as auditory cues to be more important than olfactory cues when pigs had to discriminate between people. Pigs detect odor cues very well, as evidenced by their use in truffle hunting (Pacioni 1986). Therefore, it is important to control odor cues so that the test can discriminate between physiological innate responses and learned behavior (Hagl et al. 2005).

Less is known about the visual capacities of the pig, and only a few studies have addressed pigs' ability to distinguish details and shapes (visual acuity). Zonderland et al. found pigs to perform poorly when distinguishing smaller symbol sizes at close $(<600 \mathrm{~mm})$ range, but also found a large individual variation. Their animals failed to discriminate between visual cues smaller than $20 \mathrm{~mm}$ and the minimum-distinguishable visual acuity was about 0.001-0.03 (measured corresponding to Entsu et al. 1992), lower than that of cattle and humans. In contrast to Graf (1976), Zonderland et al. (2008) did not find a strong decrease in visual acuity below 12 lx (lux) for black-andwhite cues. As regards pig color vision, Tanida et al. (1991) found that two sows could discriminate blue from red and 
green, but were unable to discriminate red from green (all with the same luminosity), whereas two other animals failed to discriminate red or green from gray but could distinguish between blue and gray. The results show that pigs discriminate blue from other colors on the basis of hue rather than brightness and suggest that pigs are red-green color blind or can poorly discriminate between these colors.

\section{Auditory capacities}

The pig's hearing range is from 42 through $40,500 \mathrm{~Hz}$ (Heffner and Heffner 1992), and exceeds the human hearing range $(31-17,600 \mathrm{~Hz})$. This increases the risk of pigs being unwittingly exposed to aversive environmental noise (experimental machinery, etc.). Social vocalization plays a role in communication and recognition between pigs and can provide complex information about the identity of the sender and its arousal state (Held et al. 2009). This knowledge should be kept in mind when testing pigs in an experimental room with other animals present within hearing distance.

\section{Gustatory preferences}

Pigs appear to like sweet tastes (Kennedy and Baldwin 1972). Glaser et al. derived more specific gustatory information by testing 75 pigs in an adapted Richer-type drinking test. None of the pigs drank a bitter-tasting quinine hydrochloride solution (49 $\mathrm{mg} / \mathrm{l})$, but preferred different carbohydrate solutions to water, with sucrose being the most preferred. Seven polyols were preferred to water, with xylitol being the most preferred. Of twelve artificial or natural compounds considered sweet by humans, only acesulfame-K, alitame, dulcin, saccharin, and sucralose-D were able to elicit a preference response in pigs (Glaser et al. 2000). In a further study, 120 pigs were tested with 60 compounds perceived as sweet by humans. Lugduname and carrelame (both guanidinoacetic acid derivatives) are considered the sweetest by humans and proved to be the two most preferred compounds in pigs. (Nofre et al. 2002).

\section{Summary}

Although pigs are probably red-green color blind and probably cannot distinguish very small symbol sizes, too little is known about their visual capacities, and this has implications for task design (e.g., is poor performance caused by poor visual capacities or cognitive limitations?). Images can be projected onto touch screens during discrimination experiments or similar tasks with humans, primates, or chicken as subjects, but before we can use this approach with pigs (or use images in general), we need to know more about their visual capacities, to exclude possible false-negative results because pigs are physically incapable of performing the task. As pigs' auditory acuity is better than that of humans, tones can serve as discriminative stimuli, or as secondary or conditioned reinforcer. However, it is important that researchers are aware that pigs hear, and may be disturbed by, sounds that are inaudible to humans. Beside auditory reinforcers, sweet solutions can be used as effective reinforcers, and quinine can be added to food if an aversive taste experience is needed. Somatosensory information concerning pigs is as yet lacking, and should be further investigated.

\section{Reinforcements}

Food rewards, such as pieces of apple, chocolate raisins, M\&M chocolates, sow rolls, commercial pellets, dog biscuits, or milk replacer (for piglets) are most commonly used as reinforcers in appetitively motivated research (Croney et al. 2003; Hagl et al. 2005; Held et al. 2001b; Laughlin et al. 1999; Moustgaard et al. 2005; Siegford et al. 2008; Tanida and Nagano 1998). In order to increase motivation and the reinforcing value of food rewards, food deprivation is often applied when testing pigs (Held et al. 2001b; Held et al. 2005; Laughlin et al. 1999; Laughlin and Mendl 2000; Laughlin and Mendl 2004; Mendl et al. 1997; Moustgaard et al. 2002; Nielsen et al. 2009; Spinka et al. 1998), but is not always necessary (Arts et al. 2009; Ferguson et al. 2009). Lack of appetite (e.g., caused by treatment with drugs that can induce nausea or anorexia as side effect) (Chaput et al. 1973) should be borne in mind, as this may make the use of food rewards impossible.

Non-food reinforcers have also been used with success. Pigs are social animals that are motivated to perform a task in which access to the group (or to the sow in the case of preweaning piglets) serves as reinforcer (Siegford et al. 2008; van Rooijen 1982). Another type of reinforcer that has proved effective is light in darkness (Baldwin and Meese 1977; Chaput et al. 1973). The latter seems to be a mediocre reinforcer, but becomes more important when olfaction is removed by bulbectomy (Baldwin and Meese 1977). A dry area-in case of a water maze-(Siegford et al. 2008) and heat (Baldwin 1979; Baldwin and Meese 1977) are also effective reinforcers.

It is also important to consider the way in which the reinforcer is applied and how access to it is achieved. For example, Baldwin and Meese (1977) found pigs to work more consistently if they could push a beam with their snout intermittently, rather than constantly, to obtain light. As described in Sect. 2.1, pigs have evolved to use their nose to seek and root; their legs and hooves are not designed to make subtle motor movements and their body is not that athletic (e.g., compared to most primates' 
bodies). Thus, in order to keep animals motivated and to facilitate performance without duress, pigs should be allowed to use their snouts to reach the reinforcer or to manipulate a lever or similar mechanism. Tasks should be designed such that the required action matches one or more of the pig's natural behaviors and that the pig naturally 'understands' the task, i.e. does not require extensive trial and error trials. This facilitates task learning and will keep the animal more motivated.

\section{Tests for assessing learning and memory in pigs}

Underlying learning mechanisms

Learning and memory tasks, based on different underlying learning methods, have been administered to pigs and are briefly defined here. Examples of research involving pigs and different learning methods will be presented in subsequent sections. In Table 1, these examples are outlined point-by-point, summarizing relevant information about subjects and materials (e.g., number and age of animals, and reinforcer used).

Classical or Pavlovian conditioning studies in pigs, which imply learning about relations between stimuli, with one stimulus signaling the occurrence of the other (Rescorla 1988), were used in the early 1900s. Although Pavlov apparently thought that pigs could not be used as experimental subjects (Moore and Marcuse 1945), evidence has since accumulated that pigs can easily be conditioned (Kratzer 1971), using classical conditioning methods. Yet only a few classical conditioning studies have used pigs, as reviewed in the Sect. 3.2.

When the response to a stimulus is followed by a reinforcer, the probability that the response will be made is increased. This is called operant conditioning or instrumental learning (Rescorla 1988). Yerkes and Coburn (1915) were probably the first to study operant conditioning in pigs, and since then operant conditioning has become a commonly used conditioning technique. Different types of reinforcers, both aversive and appetitive, have been used.

\section{Spatial tasks}

Spatial learning and the memory ability of animals can be assessed using different types of mazes, the so-called sequential choice or 'alley' mazes and 'free-choice' mazes. The alley mazes consist of a fixed starting position and one correct route to a fixed goal position, where incorrect alternatives such as visits to blind alleys or going back must be avoided. In contrast to 'alley' mazes, in 'freechoice' spatial discrimination tasks (Bouger and van der Staay 2005; Crannell 1942; Lachman and Brown 1957), rewards can be found in different places, and the animal is free to visit and revisit these baited places and unbaited alternatives, in whatever order it wishes. Once an animal has visited a place and consumed the food pellet, its revisits to the same location remain unreinforced. The most efficient behavior is to visit only baited locations, and to visit them only once. In spatial memory tasks, an animal must remember a list of places already visited in order to avoid revisits. This list of visits is held in the working memory (Olton and Samuelson 1976), and the information it contains is relevant only within a specific trial. The reference memory (Olton and Samuelson 1976) holds trial-independent information about, for example, the locations where the food reward can be found. Working memory and reference memory can be assessed simultaneously in freechoice mazes. As most variants of T- and Y-maze tasks for pigs are not based on the orientation of the animal in relation to the space it finds itself in, the pig variants of these tests will not be considered as spatial but as operant (or in some cases social) tasks.

\section{Recognition tasks}

The object recognition test (ORT) was developed by Ennaceur et al. for assessing 'trial-unique' memory in rodents (Ennaceur et al. 1989; Ennaceur and Delacour 1988; Ennaceur and Meliani 1992), based on the known preference of rodents to explore unknown objects more than familiar ones. The ORT provides measures of exploration, habituation, and discrimination, i.e., non-cognitive effects of experimental manipulations can be distinguished from effects on memory performance (Sik et al. 2003).

Similar results are obtained when the ORT is used to test social recognition and memory. Thor and Holloway (1982) studied this behavior in rats by re-exposing animals successively to familiar or unfamiliar conspecifics with differing inter-exposure intervals, and the cumulative duration of investigatory behavior was measured during re-exposure. In pigs, social recognition tends to be studied in a simultaneous setting (i.e., exposing the animal to different conspecifics at the same time), in a Y-maze (Kristensen et al. 2001; McLeman et al. 2005). For example, the recognition of humans by pigs was investigated by displaying familiar and non-familiar humans simultaneously in a Y-maze (Koba and Tanida 1999; Tanida and Nagano 1998). Another variant of social learning studied in pigs is observational learning (e.g., Held et al. 2000). Held describes it as studying social tactics (i.e., the 'exploitation of knowledge of others' or 'deceptive tactics'). Although it is not behavioral imitation as such, this definition comes close to the definition 'the capability to imitate a demonstrator's behavior', a type of learning often studied in monkeys and apes (Choleris and Kavaliers 1999). 
Table 1 Cognitive tasks performed in pigs

\begin{tabular}{|c|c|c|c|c|c|c|c|}
\hline Task & $\begin{array}{l}\text { Tested cognitive } \\
\text { ability/abilities }\end{array}$ & $N$ & Sex & Reinforcer & $\begin{array}{l}\text { Age } \\
\text { (or weight) }\end{array}$ & $\begin{array}{l}\text { Food restriction } \\
\text { schedule }\end{array}$ & Author \\
\hline \multicolumn{8}{|l|}{ Classical conditioning tasks } \\
\hline \multicolumn{8}{|l|}{ Appetitive learning } \\
\hline $\begin{array}{l}\text { Conditioned salivary } \\
\text { response }\end{array}$ & Association learning & 2 & $\mathrm{~F}$ & Food & 6 weeks & Unknown & $\begin{array}{l}\text { Moore and Marcuse } \\
\text { (1945) }\end{array}$ \\
\hline \multicolumn{8}{|l|}{ Aversive learning } \\
\hline $\begin{array}{l}\text { Conditioned aversive } \\
\text { response }\end{array}$ & Association learning & $50-64$ & $?$ & - & $75-135$ days & - & $\begin{array}{l}\text { Noble and Adams } \\
\text { (1963) }\end{array}$ \\
\hline \multicolumn{8}{|l|}{ Operant conditioning tasks } \\
\hline $\begin{array}{l}\text { Multiple choice } \\
\text { apparatus }\end{array}$ & $\begin{array}{l}\text { Ideational problem } \\
\text { solving }\end{array}$ & 2 & $\mathrm{~B} / \mathrm{F}$ & Food & 2 months & Unknown & $\begin{array}{l}\text { Yerkes and Coburn } \\
\text { (1915) }\end{array}$ \\
\hline \multicolumn{8}{|l|}{ Appetitive learning } \\
\hline $\begin{array}{l}\text { Conditioned } \\
\text { suppression of operant } \\
\text { responding }\end{array}$ & Learning ability & 12 & $\mathrm{~B} / \mathrm{F}$ & Food & $2-4$ months & Unknown & $\begin{array}{l}\text { Baldwin and Stephens } \\
\text { (1973) }\end{array}$ \\
\hline Lever pressing & $\begin{array}{l}\text { Hierarchy behavior and } \\
\text { social learning }\end{array}$ & 64 & $\mathrm{~B} / \mathrm{F}$ & Commercial pellets & $20-40 \mathrm{~kg}$ & $\begin{array}{l}\text { Abstention } 24 \mathrm{~h} \\
\text { pre-testing }\end{array}$ & $\begin{array}{l}\text { Baldwin and Meese } \\
\text { (1979) }\end{array}$ \\
\hline Panel switching & Preference testing & 66 & $\mathrm{~B} / \mathrm{F}$ & Sweetened water & $2-4$ months & Fed 1x daily & $\begin{array}{l}\text { Kennedy and Baldwin } \\
\text { (1972) }\end{array}$ \\
\hline Lever pressing & Learning ability & 84 & $\mathrm{M} / \mathrm{F}$ & Unknown & 15-17 weeks & Ad libitum & Sneddon et al. (2000) \\
\hline Lever pressing & Measure of motivation & 6 & $\mathrm{~F}$ & Unknown & 4.5 months & Fed $2 x$ daily & Ferguson et al. (2009) \\
\hline $\begin{array}{l}\text { Temporal response } \\
\text { differentiation training }\end{array}$ & Time perception & 3 & $\mathrm{~F}$ & Unknown & 4.5 months & Fed $2 x$ daily & Ferguson et al. (2009) \\
\hline $\begin{array}{l}\text { Incremental repeated } \\
\text { acquisition }\end{array}$ & Learning ability & 3 & $\mathrm{~F}$ & Unknown & 4.5 months & Fed $2 x$ daily & Ferguson et al. (2009) \\
\hline $\begin{array}{l}\text { Discrimination reversal } \\
\text { test }\end{array}$ & Reversal learning & 34 & $\mathrm{M} / \mathrm{F}$ & Food & $>35$ days & $\begin{array}{l}\text { Unknown } \\
\text { deprivation } \\
\text { schedule }\end{array}$ & $\begin{array}{l}\text { Lien and Klopfer } \\
\text { (1978) }\end{array}$ \\
\hline Reversal learning & Learning ability & 60 & $\mathrm{~B} / \mathrm{F}$ & Commercial pellets & 8 weeks & Ad libitum & Bolhuis et al. (2004) \\
\hline T-maze & Discrimination learning & 4 & $\mathrm{~F}$ & Food & 21-42 days & Unknown & Tanida et al. (1991) \\
\hline Y-maze & $\begin{array}{l}\text { Discrimination/ } \\
\text { recognition learning }\end{array}$ & 5 & M & Raisins & 8 weeks & Unknown & $\begin{array}{l}\text { Tanida and Nagano } \\
\text { (1998) }\end{array}$ \\
\hline Y-maze & $\begin{array}{l}\text { Discrimination/ } \\
\text { recognition learning }\end{array}$ & 6 & $\mathrm{~F}$ & Raisins & 8 weeks & Fed $2 x$ daily & $\begin{array}{l}\text { Koba and Tanida } \\
\text { (1999) }\end{array}$ \\
\hline $\begin{array}{l}\text { Standard human } \\
\text { approach test }\end{array}$ & Association learning & $24-36$ & $\mathrm{~F}$ & $\begin{array}{l}\text { Commercial finisher } \\
\text { ration }\end{array}$ & 17-23 weeks & Fed $1 x$ daily & $\begin{array}{l}\text { Hemsworth et al. } \\
\text { (1996) }\end{array}$ \\
\hline Discrimination learning & $\begin{array}{l}\text { Spatial, visual and } \\
\text { olfactory learning }\end{array}$ & 4 & $\mathrm{~B}$ & $\begin{array}{l}\text { Milk-bone dog } \\
\text { biscuits }\end{array}$ & $2.5-3$ years & No restrictions & Croney et al. (2003) \\
\hline Eight-arm radial maze & $\begin{array}{l}\text { Discrimination learning } \\
\text { and memory }\end{array}$ & 53 & Unknown & Milk replacer & 3 days & Fed $4 x$ daily & Wang et al. (2007) \\
\hline Set-shifting procedure & $\begin{array}{l}\text { Spatial, visual, reversal } \\
\text { and extra-dimensional } \\
\text { learning }\end{array}$ & 16 & $\mathrm{M} / \mathrm{F}(\mathrm{c})$ & M\&M chocolates & 4 months & $\begin{array}{l}70 \% \text { of daily } \\
\text { ration }\end{array}$ & $\begin{array}{l}\text { Moustgaard et al. } \\
\text { (2004) }\end{array}$ \\
\hline $\begin{array}{l}\text { Conditional go/no-go } \\
\text { task }\end{array}$ & Learning ability & 14 & $\mathrm{M} / \mathrm{F}(\mathrm{c})$ & M\&M chocolates & 5-5.5 months & $\begin{array}{l}70 \% \text { of daily } \\
\text { ration }\end{array}$ & $\begin{array}{l}\text { Moustgaard et al. } \\
\text { (2005) }\end{array}$ \\
\hline Food covering & $\begin{array}{l}\text { Discrimination learning } \\
\text { (non-visual) }\end{array}$ & $20-25$ & $\mathrm{~F}$ & Milk replacer & $1-12$ days & Unknown & Friess et al. (2007) \\
\hline Glass barrier task & Problem-solving skills & $20-25$ & $\mathrm{~F}$ & Milk replacer & $1-12$ days & Unknown & Friess et al. (2007) \\
\hline \multicolumn{8}{|l|}{ Aversion learning } \\
\hline Avoidance conditioning & Learning ability & 84 & $\mathrm{~B} / \mathrm{F}$ & Unknown & $\begin{array}{l}40 / 80 / \\
150 \text { days }\end{array}$ & Unknown & Kratzer (1969) \\
\hline Avoidance conditioning & Learning ability & 50 & $\mathrm{M} / \mathrm{B} / \mathrm{F}$ & Light & $3-6$ months & Unknown & Chaput et al. (1973) \\
\hline Avoidance conditioning & $\begin{array}{l}\text { Excitement and } \\
\text { emotionality }\end{array}$ & 120 & Unknown & Inapplicable & 21 days & Unknown & Hammel et al. (1975) \\
\hline
\end{tabular}


Table 1 continued

\begin{tabular}{|c|c|c|c|c|c|c|c|}
\hline Task & $\begin{array}{l}\text { Tested cognitive } \\
\text { ability/abilities }\end{array}$ & $N$ & Sex & Reinforcer & $\begin{array}{l}\text { Age } \\
\text { (or weight) }\end{array}$ & $\begin{array}{l}\text { Food restriction } \\
\text { schedule }\end{array}$ & Author \\
\hline Avoidance conditioning & $\begin{array}{r}\text { Learning ability/Ability } \\
\text { of response inhibition }\end{array}$ & 18 & M & Inapplicable & 3 weeks & $\begin{array}{l}\text { Low calorie/low } \\
\text { protein/ad. lib. }\end{array}$ & Barnes et al. (1969) \\
\hline Preference test & $\begin{array}{l}\text { Time perception and } \\
\text { anticipation of future } \\
\text { events }\end{array}$ & 12 & $\mathrm{~F}(\mathrm{p})$ & $\begin{array}{l}\text { Commercial } \\
\text { pellets }\end{array}$ & 8 months & $\begin{array}{l}\text { Restricted } \\
\quad \text { (unknown \%) }\end{array}$ & Spinka et al. (1998) \\
\hline \multicolumn{8}{|c|}{ Spatial learning and memory tasks } \\
\hline \multicolumn{8}{|l|}{ Alley mazes } \\
\hline $\begin{array}{l}\text { Three-choice point water } \\
\text { maze }\end{array}$ & $\begin{array}{l}\text { Spatial learning and } \\
\text { memory }\end{array}$ & 120 & Unknown & Unknown & 45 days & Unknown & Hammel et al. (1975) \\
\hline $\begin{array}{l}\text { Adjusted Hebb-Williams } \\
\text { maze }\end{array}$ & $\begin{array}{l}\text { Learning ability and } \\
\text { (long-term) memory }\end{array}$ & 48 & $\mathrm{~B} / \mathrm{F}$ & $\begin{array}{l}\text { Commercial } \\
\text { pellets }\end{array}$ & $11 / 20$ weeks & $\begin{array}{l}\text { Abstention } 12 \mathrm{~h} \\
\text { pre-testing }\end{array}$ & Jong et al. (2000) \\
\hline Spatial maze & $\begin{array}{l}\text { Spatial learning and } \\
\text { memory }\end{array}$ & 27 & $\mathrm{~B} / \mathrm{F}$ & Sow and litter & 5 days & Ad libitum & Siegford et al. (2008) \\
\hline $\begin{array}{l}\text { Modified Morris water } \\
\text { maze }\end{array}$ & $\begin{array}{l}\text { Spatial learning and } \\
\text { memory }\end{array}$ & 27 & $\mathrm{~B} / \mathrm{F}$ & $\begin{array}{l}\text { A dry location } \\
\text { (platform) }\end{array}$ & 14 days & Ad libitum & Siegford et al. (2008) \\
\hline \multicolumn{8}{|l|}{ Free-choice mazes } \\
\hline Foraging arena & $\begin{array}{l}\text { Spatial learning and } \\
\text { memory }\end{array}$ & 8 & M & Unknown & $48.06 \pm 1.72 \mathrm{~kg}$ & $80 \%$ of daily ration & Mendl et al. (1997) \\
\hline Eight-arm radial maze & $\begin{array}{l}\text { Spatial learning and } \\
\text { memory }\end{array}$ & 10 & M & Sow rolls & $30-35 \mathrm{~kg}$ & $70 \%$ of daily ration & Laughlin et al. (1999) \\
\hline Multi-room maze & Learning abilities & 27 & $\mathrm{~F}$ & Apple & 3-4 months & Unknown & Hagl et al. (2005) \\
\hline Eight-arm radial maze & $\begin{array}{l}\text { Spatial learning and } \\
\text { memory }\end{array}$ & 20 & M & Sow rolls & $30-35 \mathrm{~kg}$ & $75 \%$ of daily ration & $\begin{array}{l}\text { Laughlin and Mendl } \\
\text { (2000) }\end{array}$ \\
\hline Eight-arm radial maze & $\begin{array}{l}\text { Spatial learning and } \\
\text { memory }\end{array}$ & 16 & M & Sow rolls & $10-12$ weeks & $80 \%$ of daily ration & $\begin{array}{l}\text { Laughlin and Mendl } \\
\text { (2004) }\end{array}$ \\
\hline Spatial arena & Spatial learning & 84 & $\mathrm{M} / \mathrm{F}$ & Unknown & 15-17 weeks & Ad libitum & Sneddon et al. (2009) \\
\hline Cognitive holeboard & $\begin{array}{l}\text { Spatial learning and } \\
\text { memory }\end{array}$ & 20 & F & $\begin{array}{l}\text { Chocolate } \\
\text { raisin }\end{array}$ & 13 weeks & $\begin{array}{l}\text { Restricted } \\
\quad \text { (unknown \%) }\end{array}$ & Arts et al. (2009) \\
\hline $\begin{array}{l}\text { Restricted retrieval choice } \\
\text { test }\end{array}$ & $\begin{array}{l}\text { Spatial discrimination } \\
\text { and memory }\end{array}$ & 9 & $\mathrm{~F}$ & Sow rolls & $28.8 \mathrm{~kg} \pm 2.42$ & $80 \%$ of daily ration & Held et al. (2005) \\
\hline $\begin{array}{l}\text { T-Maze (delayed non- } \\
\text { match to sample task) }\end{array}$ & $\begin{array}{l}\text { Spatial learning and } \\
\text { memory }\end{array}$ & 8 & $\mathrm{~B}$ & $\begin{array}{l}\text { Mini-pellets in } \\
\text { water }\end{array}$ & $12-14$ months & $70 \%$ of daily ration & Nielsen et al. (2009) \\
\hline \multicolumn{8}{|l|}{ Recognition tasks } \\
\hline \multicolumn{8}{|l|}{ Object recognition } \\
\hline $\begin{array}{l}\text { Spontaneous object } \\
\text { recognition }\end{array}$ & $\begin{array}{l}\text { Object recognition } \\
\text { memory }\end{array}$ & 8 & M & - & 13 months & $\begin{array}{l}\text { Restricted } \\
\quad \text { (unknown \%) }\end{array}$ & $\begin{array}{l}\text { Moustgaard et al. } \\
(2002)\end{array}$ \\
\hline $\begin{array}{l}\text { Spontaneous object } \\
\text { recognition }\end{array}$ & $\begin{array}{l}\text { Object recognition } \\
\text { memory }\end{array}$ & 16 & M & - & 12-14 months & Fed 2x daily & Kornum et al. (2007) \\
\hline $\begin{array}{l}\text { Spontaneous object } \\
\text { recognition }\end{array}$ & $\begin{array}{l}\text { Object recognition } \\
\text { memory }\end{array}$ & 64 & $\mathrm{~B} / \mathrm{F}$ & - & 27 days & Unknown & Gifford (2005) \\
\hline $\begin{array}{l}\text { (Modified) spontaneous } \\
\text { object recognition }\end{array}$ & $\begin{array}{l}\text { Object recognition } \\
\text { memory }\end{array}$ & 36 & $\mathrm{~B} / \mathrm{F}$ & - & 35 days & Ad libitum & Gifford et al. (2007) \\
\hline \multicolumn{8}{|l|}{ Social recognition } \\
\hline $\begin{array}{l}\text { Social recognition based } \\
\text { on olfactory cues }\end{array}$ & $\begin{array}{l}\text { Social discrimination/ } \\
\text { recognition learning }\end{array}$ & 2 & Unknown & $\begin{array}{l}\text { Commercial } \\
\text { pellets }\end{array}$ & 6-9 months & Unknown & Meese et al. (1975) \\
\hline Y-maze & $\begin{array}{r}\text { Social discrimination/ } \\
\text { recognition learning }\end{array}$ & 32 & M & - & $6-7$ weeks & Ad libitum & Kristensen et al. (2001) \\
\hline $\begin{array}{l}\text { Habituation- } \\
\text { dishabituation procedure }\end{array}$ & Social discrimination & 22 & $\mathrm{~F}$ & - & 10 weeks & Ad libitum & Mendl et al. (2002) \\
\hline Y-maze & $\begin{array}{r}\text { Social discrimination/ } \\
\text { recognition learning }\end{array}$ & 12 & $\mathrm{~F}$ & Raisins & 6 weeks & Ad libitum & McLeman et al. (2005) \\
\hline
\end{tabular}


Table 1 continued

\begin{tabular}{|c|c|c|c|c|c|c|c|}
\hline Task & $\begin{array}{l}\text { Tested cognitive } \\
\text { ability/abilities }\end{array}$ & $N$ & Sex & Reinforcer & $\begin{array}{l}\text { Age } \\
\text { (or weight) }\end{array}$ & $\begin{array}{l}\text { Food restriction } \\
\text { schedule }\end{array}$ & Author \\
\hline Social recognition test & $\begin{array}{r}\text { Social discrimination/ } \\
\text { recognition learning }\end{array}$ & $120-132$ & $\mathrm{M} / \mathrm{F}$ & - & 11-13 days & Ad libitum & De Souza et al. (2006) \\
\hline Y-maze & Social discrimination & 12 & $\mathrm{~F}$ & Raisins & Juvenile & $\begin{array}{c}\text { Removed between } \\
8 \mathrm{am}-12 \mathrm{pm} \text { and } \\
13 \mathrm{pm}-17 \mathrm{pm}\end{array}$ & McLeman et al. (2008) \\
\hline \multicolumn{8}{|l|}{ Observational learning } \\
\hline $\begin{array}{l}\text { 'Informed forager' } \\
\text { paradigm }\end{array}$ & $\begin{array}{l}\text { Exploitation of } \\
\text { knowledge of others }\end{array}$ & 16 & $\mathrm{~F}$ & Unknown & $>29.87 \mathrm{~kg}$ & $70 \%$ of daily ration & Held et al. (2000) \\
\hline $\begin{array}{l}\text { Adapted Guesser-Knower } \\
\text { experiment }\end{array}$ & $\begin{array}{l}\text { Exploitation of } \\
\text { knowledge of others }\end{array}$ & 18 & $\mathrm{~F}$ & $\begin{array}{l}\text { Commercial } \\
\text { pellets }\end{array}$ & Juvenile & $70 \%$ of daily ration & Held et al. (2001) \\
\hline \multicolumn{8}{|l|}{ Awareness } \\
\hline Mirror Test & $\begin{array}{l}\text { Object/information } \\
\text { use }\end{array}$ & 19 & $\mathrm{M} / \mathrm{F}$ & Food & $4-8$ weeks & Ad libitum & Broom et al. (2009) \\
\hline
\end{tabular}

Task Name of the experiment performed. Tested cognitive ability/abilities Type of cognition measured during the experiment. $N$ Amount of animals applied during the experiment. Sex: $F$ female/sow, $M$ male/intact boar, $B$ castrated male/barrow. Reinforcer Type of reinforcement applied. Age Age of animals at the beginning of the experiment, or if unknown, weight of animal at the beginning of the experiment. Food restriction schedule If applied, type of restriction schedule. Author Researcher(s) performing the experiment

\section{Awareness}

Animals' awareness or the ability to perceive, feel, or be conscious of events or objects can be studied by investigating their use of tools. Such studies usually involve primates and corvids, which are physically equipped to use tools with their paws or beak, whereas pigs are not capable of doing this. However, mirrors, and the information obtained from them, were recently used to demonstrate awareness in pigs (Broom et al. 2009).

Classical conditioning tasks

\section{Appetitively motivated tasks}

In a small-scale study with two pigs, Moore and Marcuse (1945) examined 4 types of conditioning, including classical conditioning. They attempted to establish a 'conditioned salivary response' in an experimental setting similar to that used by Pavlov. Pigs equipped with a parotid fistula were trained to tolerate restraint on a platform. A tone (the conditioned stimulus, CS) was presented, immediately followed by food (the unconditioned stimulus, US). Both pigs established a stable, but not equally large, conditioned salivary response. In addition, the response was more profound in a laboratory setting than during feeding in the home pen, which is a less-controlled environment. Feeding time was signaled about $5 \mathrm{~min}$ in advance and elicited a conditioned salivary response in 100 and $75 \%$ of the trials in the laboratory, but only in 67 and $6.7 \%$ of the trials performed in the home pen.

\section{Aversively motivated tasks}

Noble and Adams (1963) examined the effect of interval length between a CS and an US on classical conditioning performance using Duroc pigs in two different experiments. In the first experiment, the CS-US interval ranged between 0.5 and $2 \mathrm{~s}$, the CS was an increase in illumination, and the US was an electric shock to a hind leg. In the second experiment, the CS was a combination of an increase in illumination and a vibratory-auditory cue from a buzzer strapped to the neck behind the subjects' ear, the CS-US interval was $1,2,4$, and $8 \mathrm{~s}$ ), and the US was as in the first experiment. The conditioned response (CR) of the animals after several trials was described as a 'bracing' posture. The CR was found to be more pronounced with increasing CS-US interval. This might partly be caused by the increased opportunity to respond to the prospective US.

These experiments support the notion that pigs can be classically conditioned using an aversive or appetitive US. However, it has not been proven that the length of the CSUS interval is the sole determinant of the presence and intensity of the CR. Probably because classical conditioning experiments are of limited interest to cognitive researchers, these relatively sensitive and automated experiments have not been followed up.

Operant conditioning tasks

Most operant conditioning studies have been performed using either positive (appetitive) or negative (aversive) reinforcers. Yerkes and Coburn (1915) decided to make use 
of both variants in an operant conditioning experiment with two Chester White pigs. The apparatus, situated in a meadow, consisted of 9 similar boxes and food troughs. The experimenters presented 4 different 'problems' to the pigs. The correct operant response required to receive a food reward was to choose the correct entry door out of several opened boxes. A wrong entry was punished with 1 min of confinement in the box. Entry into the correct box led to a filled food trough. The pigs acquired the task, but when one 'problem' was replaced by another problem, the second problem was solved more slowly, probably caused by proactive interference. Yerkes and Coburn commented that this research was a clever way to gain information about the ability of pigs to adjust themselves to fairly simple, but novel, situations (this is what they named ideational problem solving). It was several decades after this seminal study that learning experiments with pigs were repeated using an operant conditioning setting.

\section{Appetitive learning}

In the 1960s and 1970s, Baldwin et al. studied the pig extensively in several operant conditioning experiments. In 1973, they trained, within an hour, pigs that were loosely restrained in a metal stand to press levers with their snout for a food reward. The authors suggested that the pigs acquired the task so rapidly because the experimental environment was not new to them: the pigs had previously been trained in a thermal reinforcement experiment (Baldwin and Stephens 1973).

Food-rewarded panel switching was used by Kennedy and Baldwin (1972) to study taste preferences in pigs. Differing amounts of nutritive and non-nutritive sweeteners were added to water, and a progressive ratio (PR) schedule of reinforcement (i.e., the number of responses needed to earn a reward increased during the course of the study) was applied for each sweetener separately. It was found that pigs were willing to work to very high break points (the point at which they were no longer willing to work for the reward) to obtain sucrose and glucose, and to high break points for saccharin (Kennedy and Baldwin 1972). This is one of the studies (see 'Sensory capacities') confirming that pigs like sweet tastes. Sneddon et al. (2000) applied a reinforcement schedule with fixed ratio 2 and 3 (i.e., every second or third lever press was rewarded) during a leverpress experiment. Boars and gilts were housed in barren or enriched environments. No gender differences were found, but in general animals from an enriched housing environment acquired this task more rapidly.

Recently, Ferguson et al. (2009) exposed 6 female Yucatan minipigs to a food reinforced lever-pressing experiment. They applied a progressive ratio reinforcement (PR) schedule (PR1 +2 , i.e. in each successive trial, 2 more lever presses were needed to gain the reward than in the previous trial). The response rates of these prepubertal minipigs ranged between 0.48 and 1.99 lever presses per second. This means that, on this task, pigs have higher response rates than rats (which show lower response rates) but lower response rates than non-human primates (which show higher response rates). Ferguson reused the minipigs in a 'temporal response differentiation training' task, in which a reward was given when the lever was held down for a minimum of 10 and maximum of $14 \mathrm{~s}$. Acquisition of this task was poor, but the researchers presumed that this was more likely the result of the apparatus and the physical response of the minipig (hooves easily slipped off of the lever) than the difficulty of the task itself. The last operant test used, involving 3 of the 6 minipigs from previous experiments, was 'incremental repeated acquisition', a progressive task in which in every trial several levers have to be pressed in a different order. Again, acquisition of this task was relatively poor, but the study lasted only for a short time and food deprivation was not applied. The design of these experiments was not optimal because the number of pigs was limited, training could not be continued long enough, and the apparatus was not adapted to pigs. Still, these studies support the notion that automated conditioning equipment can be used to present tasks of varying difficulty, which means that it is possible to compare the performance of rodents and pigs.

Apart from Skinner box-like operant lever-pressing experiments, various other positively reinforced operant conditioning tasks have been used. In a study investigating early development and later learning, Lien and Klopfer (1978) trained pigs in a discrimination reversal test. Piglets that showed a very strong preference for a particular teat (termed 'stereotyped suckling' by Lien and Klopfer) were compared with piglets that varied their suckling position. In an operant test comparing these 2 groups, hog pellets could be obtained by responding to the correct response panel on the stimulus apparatus lowered into the pen (presented together with a light cue). The apparatus was retracted after the pigs made a response. The automatic feeder was placed in another corner of the room. When the piglets had reached a preset learning criterion, they were trained on reversal of this problem (i.e., instead of responding on the side where the stimuli appeared, responding at the opposite side was rewarded). While there were minimal differences in task acquisition between the 2 groups of piglets, reversal learning appeared to be more difficult for piglets that showed strong teat preferences before weaning. Although 'teat order' is generally considered to be stable in piglets (i.e., Fraser and Thompson 1991), rendering the term 'stereotyped suckling' somewhat unsuitable, Lien \& Klopfer showed that these learning experiments can be useful to investigate behavioral problems that are related to early development. 
In 2004, Bolhuis et al. studied reversal learning in a T-maze, using pigs from 8 litters (housed in barren or enriched environments). These animals were first tested twice in a back-test (restraining a piglet for $60 \mathrm{~s}$ on its back) and classified as high- or low-responding according to the number of escape attempts. During training, one arm of the T-maze contained bait, but during 6 consecutive trials this arm did not contain bait, or an intramaze change was applied (placing of a novel object in the baited arm). During training trials, no housing, back-test classification, or sex differences were found. However, the reversal trials revealed low-responding piglets to perform better (i.e., they entered the new baited arm more often) than highresponding piglets. When an intra-maze change was applied, an interaction between housing and back-test classification was found: high responders from a barren environment spent more time investigating the novel object than low-responders from the same environment. However, low-responders from an enriched environment were found to be more distracted than the enriched housed high responders. Thus, although pigs learn this type of T-maze discrimination learning task relatively rapidly (i.e., the task is relatively simple), differences between groups of pigs can be detected by increasing the difficulty of the task, by introducing a reversal. Interestingly, coping style seemed to be related to performance.

Tanida et al. (1991) investigated whether pigs are able to discriminate between green, blue, and red, using a T-maze. Two female weanling pigs were trained to discriminate pairwise between the 3 colors. Additionally, 2 other weanlings were trained to discriminate pairwise between gray and 1 of the 3 colors (all colors had the same luminosity). All animals were able to discriminate between blue and all other colors, but not between green and red and green or red versus gray (Tanida et al. 1991). More about visual performance studies can be read in 'Sensory capacities'.

In an operant conditioning task, Tanida and Nagano (1998) trained pigs to discriminate between a familiar and an unknown handler in a Y-maze. Animals had to respond to the familiar handler by entering the arm of the maze in which that person was present. A correct choice was rewarded with chocolate raisins. To find out pigs' responses to changes in visual, auditory, and olfactory cues, hints were changed one at a time (i.e., no calling of the pig or wearing the same perfume anymore). This study demonstrated that pigs are able to discriminate between humans. Visual and auditory cues seemed to be more important than olfactory cues, but the variation in individual performance was large. In 1999, the handler discrimination experiment was repeated by Koba and Tanida, but this time visual cues seemed to be the most discriminative factor: when all handlers wore the same color clothes, only a few pigs were able to make the correct choice (Koba and Tanida 1999).
To gain insight into human-avoidance behavior, Hemsworth et al. (1996) studied pigs' associative learning capacities in a human approach test. Three groups of sows received different types of treatment given by humans (e.g., a boar was introduced daily to the sow by a handler, or 'back pressure treatment' was applied daily by a handler, or the sow was minimally treated by a handler) during 2 estrus periods with or without the presence of food before being exposed to the test. During testing, all behaviors directed toward the human were scored. Hand-fed pigs were found to be less fearful, taking a shorter time to approach the experimenter.

The above experiments revealed that pigs can distinguish between familiar and unfamiliar persons. This knowledge could be used to improve animal welfare. However, because these experiments investigated not only on the pig's memory, but also its sensory capacities such as sight, smell, and hearing, although not distinct from each other, future studies should try to separate the different sensory cues from each other.

Croney et al. (2003) applied relatively simple operant discrimination learning tests in pigs. Four minipig boars were trained to discriminate between colors (orange or green) or olfactory stimuli (coconut or almond) to earn a food reward. An experimenter used a clicker directly after a correct choice was made, and the pig approached the experimenter to obtain its reward. Pigs could discriminate between cues, and when the task presented multiple choices simultaneously (2-10 smells or colors), pigs were still able to respond to the correct stimulus. Croney et al. suggested that the animals might have formed a general learning set that transferred across tests with varying amounts of simultaneous choices. What remains unknown from this experiment is the number of sessions (10 trials/ session) needed to reach criterion of learning for each new phase in which one stimulus was added. This omission makes it hard to interpret how easily pigs learn to discriminate between 2 or more visual or olfactory stimuli.

Using a non-spatial version of the radial-arm maze, Wang et al. (2007) studied 2 learning tests ('easy' and 'difficult') in succession. A visual cue (1 versus 3 black dots in the easy and 2 versus 3 black dots in the difficult task) was used, and the arm marked with 3 black dots hid accessible milk replacer. In both tests, 40 trials were given divided over 5 and 6 days, respectively. Memory was tested 2 days after completion of a set of trials, by presenting the same task again in one trial. Pigs were able to acquire both the easy and the difficult tasks, but criterion level was reached in fewer trials during the 'difficult' task, suggesting that previous acquisition of an 'easy' task facilitates the acquisition of a subsequent harder task. Pigs supplemented with sialic acid (possibly a conditional nutrient during rapid brain growth) acquired both tasks in 
fewer trials; however, it cannot be ruled out other domains, such as motivation, were affected. Memory was also positively influenced by sialic acid ( 2 days after completion of a set of learning trials, a single memory test of one trial only was performed), with the sialic acid-supplemented animals having higher scores than the controls. These results show that this visual discrimination task could be used to study the effects of putative cognition enhancers.

Moustgaard et al. (2004) trained Göttingen minipigs on black-white (visual) and right-left (spatial) discrimination by teaching them to put their nose in a response hole for a food reward. After acquisition of the discrimination task, it was investigated whether the pigs paid attention to particular stimulus dimensions by applying an extra-dimensional shift procedure (changing the stimulus dimension from visual to spatial or the other way around). Stimulus dimensions were not found to be important and nor was the pig's sex, with boars and sows reaching the same level of performance. More recently (2005), Moustgaard et al. trained minipigs in a right-left discrimination task followed by a go/no-go task. To acquire the left-right discrimination task, animals were trained to respond in the left hole when both holes turned black and to respond in the right hole when both holes turned white. During the go/nogo task, pigs were rewarded with food if they responded when both holes turned blue and were mildly 'punished' (20 s of darkness) if they responded when both holes turned red. All pigs reached the criterion of $>90 \%$ correct choices per session for the right-left discrimination task and nearly all reached this level for the go/no-go task.

Moustgaard et al. provided information about the time needed to train pigs in their visual and spatial discrimination tasks, information that unfortunately is missing in many other studies. Two out of 16 minipigs were not able to reach criterion of learning during the 1 st step of the shaping phase (putting the snout in a response hole), and 2-15 sessions of 40 trials each were needed for the next step of the shaping phase. Criterion during the last step of the shaping phase was reached in $2-11$ sessions. During the actual discrimination experiment, it took the animals 1-20 sessions of 20 trials each to learn the discrimination or reversal. This schedule for extensive training and pretraining shows that discrimination experiments with pigs can be very time-consuming. Moreover, the behavior needed to perform this task might not be part of the pig's natural behavioral repertoire, which may mean that the pig cannot 'learn' the task or that it becomes demotivated.

Recently, Friess et al. (2007) examined the principle of operant learning in a 'food cover task'. Female piglets were trained to remove a plastic cover from a food dish to gain access to the hidden food within $20 \mathrm{~s}$. In a 'glass barrier task', piglets were trained to move around a transparent barrier in order to gain access to the food. These tests were part of a test battery used to obtain information about discrimination learning abilities after mild or moderate brain injury, which was induced by rapid axial head rotation. Both the brain-injured piglets and the control piglets performed the tasks at the same speed. Unlike other tests of the test battery (i.e., neurobehavioral tests such as beam walking), these learning and memory tests apparently fail to detect (subtle) deficits.

\section{Aversive learning}

During the late 1960s, Kratzer (1969) studied shockmotivated avoidance learning in Duroc and Hampshire pigs, using a shuttle box. The shock was delivered via a girth around the chest if the pig did not cross a wooden barrier when an avoidance signal (buzzer) had sounded. Tests were performed with pigs up to 160 days of age. Younger, approximately 20-day-old, pigs showed better avoidance learning (crossing the barrier) than older pigs, and heavier pigs were better learners than lighter pigs of the same age. Kratzer hypothesized that weight might be positively correlated with factors that increase learning performance, such as physiological maturity and general health. Results also clearly showed breed differences in learning, with Duroc pigs achieving higher levels of avoidance learning than Hampshire pigs, regardless of age. Because birth weight differences between low and normal birth weight piglets are known to be lasting (Rehfeldt and Kuhn 2006), one could speculate that birth weight is correlated with learning performance.

Chaput et al. (1973) trained 3- to 6-month-old pigs in a one-way shock-motivated avoidance shuttle box task in which a telephone buzzer was used as auditory CS. After the buzzer went off, pigs could avoid a subtetanizing shock by moving from a darkened to an illuminated chamber. If the pig did not cross into the illuminated chamber before the US, they were given an electric shock (max. duration $93.9 \mathrm{~s}$ ). The average level of shock avoidance was very high. In their comparison of shuttle box learning and water maze learning (an aversively motivated spatial discrimination task), Hammell et al. (1975) found that the performance of pigs on the 2 tasks was uncorrelated and concluded that these 2 tasks tap different behavioral domains (e.g., motivation, sensory requirements).

Barnes et al. (1969) exposed pigs to a conditioned avoidance procedure in a large quadrangular arena with several hurdles. Shocks could be avoided by jumping a hurdle when a CS was presented (clicking signals). After 3 training sessions, an extinction session was run (i.e., the CS was no longer followed by a shock). Pigs that were malnourished early in life displayed higher levels of excitement (ethogram to score excitement was not described) in the extinction sessions and were unable to inhibit responses 
when the CS was presented. This operant task shows how the influence of specific (negative) early life conditions can be studied in an aversively motivated operant learning task.

Time perception and anticipation of future events were measured by Spinka et al. (1998) in a preference test. Pregnant sows were trained to enter 1 of 2 rooms, each containing several feeding crates. The rooms could be reached by turning left or right from a corridor. After the sow entered a crate, it received food and the crate closed automatically. The crate opened automatically again after $30 \mathrm{~min}$ (left room) or $240 \mathrm{~min}$ (right room). After a training period (i.e., in which sows were only allowed to enter one of the rooms), most sows entered the left room with the short confinement crate, which suggests that pigs can perceive time.

\section{Spatial learning}

Alley mazes The aversively motivated three-choice point water maze (a rectangle tub in which pigs have to swim from one side to the other with three left-right choice points in-between) is an example of a spatial learning task in an 'alley' type maze. Using this water maze, Hammell et al. (1975) found that pigs $(n=120)$ could readily learn alternating (exit not visible, pig swims around barriers) but not non-alternating (exit visible straight ahead, pig swims through openings in barriers) swimming patterns. de Jong et al. (2000) studied learning and long-term memory in a dry maze with different configurations, based on the HebbWilliams maze. Piglets acquired the task at the age of 11 weeks, and retention was tested 9 weeks later. The goal of this study was to investigate whether housing in barren or enriched environments affected learning and memory. Piglets from both groups learned the maze configurations quickly, but the piglets raised in a barren environment made significantly more line crossings and had a longer latency to reach the food when the previously learned maze configuration was repeated in the retention test. De Jong et al. concluded that piglets raised in a barren environment had an impaired long-term memory compared with piglets housed in an enriched environment. The authors showed that it is possible to study postnatal influences on memory in a relatively simple maze test.

A more recent maze test designed by Siegford et al. (2008) was used to assess the effects of maze training on weaning stress in 5-day-old piglets. The maze used can be classified as an 'alley' maze, but increasingly complex variants were used. Here, instead of food, the reward was being returned to the home pen with the sow and littermates. Each piglet was randomly assigned to 1 of 3 different groups ('maze task', 'short isolation control', and 'control with sow'). Piglets that were maze trained, i.e. were exposed to cognitive challenges, showed a decreased fear of unfamiliar persons after weaning compared with control piglets housed under the same conditions. The authors also investigated whether early cognitive experiences influence learning ability. This was tested in a "water maze spatial memory task' $\left(38-39^{\circ} \mathrm{C}\right.$ heated pool with a diameter of $3.6 \mathrm{~m}$ ) similar to the Morris Water Maze (Morris 1984). The outcomes of the male piglets previously trained in the first maze were notable: they escaped onto the platform faster than did piglets that were previously exposed to short-lasting social isolation. However, no differences were found between 'control' and 'maze-tested' animals, and therefore these results cannot be indisputably ascribed to the prior cognitive experience of the piglets. More research is needed to show whether cognitive enrichment at a very young age influences cognitive performance later in life.

Free-choice mazes Most spatial learning and memory studies in pigs have used 'free-choice mazes'. For example, Mendl et al. (1997) used a foraging arena to study spatial memory and its susceptibility to disruption by environmental stimuli. Ten identical food troughs placed against the walls of the arena were covered by panels and could not be seen by the pigs. In this repeated acquisition paradigm, one trough was baited, and pigs were allowed to search for it during a sample trial. During choice trials (i.e., relocation visits), pigs found their food in fewer visits than expected by chance, but disturbances during the inter-trial interval (e.g., isolation in a novel environment) resulted in more errors made during choice trials. This indicates that pigs isolated in a novel environment are susceptible to mild disruptions of spatial memory. This task seems to be suitable to measure the influence on spatial memory of disturbances during inter-trial intervals. A possible element of the task that might need some consideration is the number of food troughs. Yerkes and Coburn (1915) applied a similar task using 9 parallel entry doors. Their results showed that pigs have difficulties discriminating between doors. They performed best on the left, right, and middle doors, but had difficulties with discriminating or remembering the in-between doors. This might also be true for the radial-arm maze experiment performed by Laughlin et al. (1999). During the first experiment, the authors baited 4 out of 8 arms, and pigs were allowed to locate and eat the food freely. Spatial memory was tested after a retention interval (10 min) with or without a disturbance factor (e.g., weighing in a crate). Pigs that were weighed took longer to find the food reward, showing that environmental stimuli can disrupt memory, in this case for baited food sites (Laughlin et al. 1999).

Recently, efforts have been made to develop learning and memory tasks for pigs in which several factors can be controlled and measured experimentally, comparable to 
what is currently standard practice for other species. For example, Hagl et al. (2005) designed a multi-room maze to study possible subtle learning impairments in pigs that suffered from induced hypothermic circulatory arrest (HCA). Six out of 8 rooms in the maze were baited with apple. During each trial, an animal was only allowed to visit one of the rooms (other doors closed directly after entry of this one room). Between trials, the animals waited in a holding area for $30 \mathrm{~s}$. Scores (i.e., decrease in the number of entries of unbaited chambers) improved over a 12-day period. A daily training session ended when all baited chambers had been visited or after 20 trials, whichever event occurred first. For the second problem (again 12 days), only the left 4 or the right 4 chambers were baited. Every day, during the second half of the trials, the baited rooms switched sides. This second problem was designed to increase the level of difficulty, to detect subtle differences in learning and memory. Learning and memory were similar in HCA animals and healthy subjects in the first task, but the performance of the HCA animals was impaired in the second task. The outcomes of this study clearly underline the importance of considering the sensitivity of a test design - too simple designs might yield false-negative results.

Laughlin and Mendl (2000) studied win-shift/win-stay strategies in pigs in a radial-arm maze. Four arms were baited, and these arms were rebaited for pigs assigned to the 'stay' strategy during the recall trial. The reward for the 'shift' pigs could be found in the 4 previously unbaited arms. The results showed that pigs are capable of using both a win-shift and a win-stay strategy, but that the task is performed faster and with a higher degree of accuracy after training in the win-shift task. When the costs to obtain food in the baited arm in the radial-arm maze were increased (i.e., more effort needed to reach the reinforcer, by placing a rope in the way) during the sampling trial in the win-stay task, the number of errors made during choice trials significantly decreased, possibly because pigs paid more attention to the baited arm.

Sneddon et al. (2000) tested pigs reared in barren and enriched environments in a spatial foraging arena. This arena was divided into 12 squares, with 7 of these squares fitted with food bowls. Only one bowl contained a food reward. The piglets (both sexes) raised in the enriched environment found the baited bowl significantly faster than the piglets raised in the barren environment. This is one of several experiments showing that an enriched rearing environment improves learning and memory.

In a spatial holeboard discrimination task, Arts et al. (2009) showed that mild mixing stress did not influence pigs' performance. Mixing stress was induced by housing a pig in a new pen together with an unfamiliar individual $1-4$ h before trials 1,5 , and 8 (13 trials in total). The test arena in which 16 buckets were symmetrically placed, measured $8 \times 7.6 \mathrm{~m}$. One entry door allowed access to the arena. After a training period, testing (consisting of 3 test phases with a total of 25,13 and 13 trials, respectively) started. Each pig $(n=20$, Finish Landrace x York F1) received its own configuration of 4 baited (chocolate covered raisins) holes. The configuration for each individual changed per test phase. Without food deprivation, pigs rapidly learned to search and collect baits and thus acquired the tasks. Performance (WM and RM) improved over test phases, and it was concluded that the animals 'learned to learn'.

A somewhat different but comparable task used by Held et al. (2005) showed the relevance of utilizing spatial tasks when investigating pigs' abilities to discriminate between food of different value. In a restricted retrieval choice test, Held et al. (2005) investigated whether domestic pigs could remember baited areas and differences in the amount and quality of the baits. In this version of a spatial memory task, 2 out of 8 possible food sites contained bait. The amount of food ( 8 versus 3 sow roll pieces) together with the addition of an obstacle (a brick) determined the relative value of each baited location. After a training period, pigs were only allowed to visit one of the food sites. The outcomes suggest that juvenile female pigs can discriminate between food sites of different value and overall choose for the site with the largest bait.

Recently, Nielsen et al. (2009) trained pigs in a reinforced T-maze alternation task to find a reward in one arm during the first trial and in the opposite arm in the second trial. The number of correct choices during several trials is a measure of spatial short-term memory. Pigs were able to perform this task with delay intervals of 60,300, and $900 \mathrm{~s}$. When treated with scopolamine (an anti-cholinergic drug that causes memory dysfunction; $0.40 \mathrm{mg} / \mathrm{kg}$ intramuscularly), the number of errors increased for all time intervals, and the speed of task performance decreased. By administering scopolamine after untreated animals had performed the task, Nielsen et al. clearly showed that this task measures memory performance, and their findings can be seen as a step forward in the validation of such tasks.

\section{Recognition tasks}

Tests that assess the recognition abilities of pigs can be subdivided into the recognition of objects, conspecifics (social recognition), and humans.

\section{Object recognition}

Moustgaard et al. (2002) demonstrated that Göttingen minipig boars are able to acquire the object recognition test (ORT). Non-castrated boars were tested because they were 
expected to be more explorative than sows. Pigs were first habituated to a test arena, and then to an arena containing 2 identical objects. One hour later, after one of these objects had been replaced by a non-familiar object, the pigs entered the arena. The boars investigated the novel object, but there was substantial variation in how long they investigated it. It was concluded that memory for objects lasted at least $1 \mathrm{~h}$. Kornum et al. (2007) found that pigs could discriminate between familiar and novel objects, as evidenced by a longer time spent investigating a novel object during the ORT, but only when the retention interval was shorter than $1 \mathrm{~h}$. The authors tested twelve different sets of objects and found that the time spent investigating the various objects was different, possibly due to differences in object preference.

In contrast, Gifford et al. reported that pigs failed to display novelty preference at any delay interval in the ORT, possibly due to the length of the exposure phase and the location where pigs were exposed to the familiar object. Unlike tests with human infants and rodents, pigs were exposed to the object in their home cage with littermates, instead of being alone. Gifford also suggested the possibility that these results were due to the lack of preference for an unfamiliar over a familiar object, even though the animal recognized the familiar object (Gifford 2005; Gifford et al. 2007). The few object recognition studies involving pigs published to date have yielded contradictory results opposite to those reported in rodent studies (which show that the animals have a stable preference for investigating a novel object (Ennaceur and Delacour 1988). Consequently, it still remains to be demonstrated that the ORT is useful to test object recognition memory in pigs.

\section{Recognition of conspecifics}

Meese et al. (1975) found that pigs could distinguish between urine samples from conspecifics. In the experimental set-up, gilts had to respond, by means of panel switching, to the correct odor stimulus in order to gain a food reward. Mendl et al. (2002) presented urine samples of unfamiliar conspecifics to 22 female Large White Landrace pigs to investigate whether they could discriminate between urinary odors of animals of similar age. In order to study this, a habituation-dishabituation procedure was applied in a control and a discrimination group. An animal was presented with a fresh urine sample from another animal for $2 \mathrm{~min}$, followed by an interexposure interval of $15 \mathrm{~min}$. After this interval, the sample was presented again for 2 min. After another 15-min interval, the sample was presented again for $2 \mathrm{~min}$. The duration of urine sample investigation was recorded. Shorter durations (habituation) were expected when a sample from the same pig was presented a second time and longer durations (dishabituation) were expected when a urine sample from a different pig was presented. The discrimination group was presented with 2 different samples from one individual and one sample from a different individual. In this experiment, which is based on investigatory behavior, Mendl et al. (2002) showed that 10-week-old gilts are able to discriminate between urine samples from conspecifics. The habituation-dishabituation procedure was successful in showing stimulus discrimination in pigs, although exploration time appeared to be the only useful measure (Mendl et al. 2002).

The ability of pigs to recognize familiar conspecifics was studied by Kristensen et al. (2001). Using a Y-maze with a familiar and an unfamiliar stimulus pig behind doors that allowed tactile, visual, and olfactory contact or olfactory contact only, the authors found that juvenile animals responded well to (familiar) social cues and concluded that pigs are able to discriminate between familiar and unfamiliar conspecifics. The variables studied were time spent in zones in close proximity to one of the conspecifics and the number of entries to those zones. This study suggests that pigs are more motivated to visit sites containing several social cues (i.e., tactile, olfactory, and visual) rather than only one such clue (olfactory). In 2005, McLeman et al. confirmed the finding that juvenile pigs could successfully discriminate between familiar littermates and unfamiliar individuals in a Y-maze. Pigs spent more time in close physical proximity to the familiar pig compared with the unfamiliar pig. De Souza (2006) also found that neonatal piglets had good short- and long-term social recognition performance and that social memory was not influenced by minor changes to the environment (relocation of sow and litter in a new pen).

The above-described studies all showed that pigs prefer staying in close proximity to familiar conspecifics if given the choice and thus confirm that pigs are able to discriminate between conspecifics. This basic knowledge about the species could be used when designing tasks to provide greater insight into social recognition in pigs (e.g., number of conspecifics recognized, long- and short-term social memory).

McLeman et al. continued their conspecific-discrimination studies using 12 Landrace $\mathrm{X}$ Large White $\mathrm{X}$ Duroc pigs. They used a Y-maze to show that pigs are able to discriminate between individual group members, using either bimodal or unimodal cues. The end of each arm of the Y-maze contained a rewarded and unrewarded stimulus pig. In this closed maze controlled for olfactory, visual, and auditory cues, pigs first had to learn a bimodal task. Animals were trained to discriminate between a pair of familiar, but unrelated littermates by using 2 of 3 sensory modalities (audition, olfaction, and vision). After the pig reached the learning criterion ( 3 consecutive sessions $8 / 10$ 
correct choices), it was transferred to a unimodal task in which discrimination was based on only 1 of the 3 modalities. Daily sessions of 10 consecutive trials were given, and approaching the correct stimulus pig was rewarded with raisins. Although 4 animals did not reach the learning criterion in the bimodal test and 2 of the 8 animals successful in the bimodal test did not reach the criterion in the unimodal test, McLeman et al. showed that pigs are able to discriminate between related group members when only 1 or 2 sensory modalities are available. The closed and controlled environment of this Y-maze provides opportunities for further studies on social discrimination and mental representations without using invasive techniques (McLeman et al. 2008).

\section{Observational learning}

Observational learning-like studies have investigated socially cued behavior in pigs. However, results do not provide clear evidence that pigs are able to imitate a conspecifics' behavior or exploit its knowledge. Baldwin and Meese (1979) observed the social behavior of 2 or 3 individuals at a time in a lever-press room. These individuals could be familiar or unfamiliar, trained to press the lever, or untrained. The authors reported that subordinate pigs pressed the lever at a low frequency and that observational learning did not occur. Dominant pigs were found to do most of the lever pressing, but lever-press frequency declined in all pigs with increasing test duration, possibly because of satiation effects (Baldwin and Meese 1979). However, it can be questioned whether observational learning can be properly investigated in this experimental set-up. Even though a pig might have learned from its conspecifics how to earn rewards, its hierarchical position within the group might prevent it from pressing the lever.

Held et al. (2000) studied this phenomenon using the 'informed forager' paradigm. In a spatial arena (see spatial memory), food was hidden in 1 of 8 buckets. A pig that had been trained to find the food entered the arena together with a heavier and non-trained pig. The results appeared to show that the non-trained pig followed the example of the trained pig rather than randomly investigating the buckets. Held described this behavior as the 'exploitation of knowledge of an individual by another pig'. Held et al. investigated observational learning further in 2001, testing the hypothesis that pigs can discriminate between companions who can see where food is hidden and companions who cannot. Results provided weak evidence for the notion that pigs have visual perspective taking abilities, i.e., the ability to appreciate what others can or cannot see (Held et al. 2001a). Because little is known about this type of cognitive ability in pigs and the tests used did not provide unambiguous evidence, further research is needed.

\section{Awareness}

Very recently, Broom et al. (2009) assessed the ability of 4-6-week-old pigs to use information acquired with a mirror to locate a reward in a food bowl. Pairs of pigs from one group $(n=8)$ were placed in a pen with a mirror for $5 \mathrm{~h}$ and a pair of pigs from the control group $(n=11)$ were placed in a standard pen. Thereafter, a 'mirror test' was performed. Each piglet was individually released in a room with a mirror. A barrier, placed against the mirror at an angle of $90^{\circ}$, divided the first two-thirds of the room. The piglet entered the room at the back on the right side. From there, it was able to see a food bowl in the mirror, placed on the other, not directly visible, side of the barrier. Piglets were allowed to walk around the barrier and the mirror. Nine of eleven control pigs first approached the mirror and then walked behind it; however, 7 of 8 piglets with mirror experience looked at the mirror, saw the food bowl, and went to the other side of the barrier to obtain the food. The mirror-experienced pigs were presented with the same setup again but with the mirror replaced by a wire mesh. The food bowl was placed behind the mesh at the same location where it had been visible before in the mirror. Of the 8 animals, 6 went to the area with the food bowl, behind the mesh. This experiment showed that piglets are able to observe and remember features of its surrounding and can act accordingly. To turn away from the mirror with the image of the food and to go around the barrier to get to the food requires piglets to have a mental map of the environment and awareness that it can access the food reward. By excluding other potential cues, such as smell and area preference, Broom et al. were able to show that pigs can learn how a mirror functions and how to exploit this knowledge. However, findings do not necessarily imply that the pigs recognized themselves, but this ability is the first step in the process of self-recognition (Macellini et al. 2010). Such studies have not yet been performed with pigs.

\section{Discussion}

The pig in cognitive research: a twofold goal

Pigs appear to be a very suitable and promising animal species for use in biomedical research investigating learning and memory (de Groot et al. 2005; Lind et al. 2007; Nunoya et al. 2007; Vodička et al. 2005), and a number of behavioral cognitive tasks have been developed using these animals (Chaput et al. 1973; Larsen and Rolin 2004; Lind et al. 2004; Mikkelsen et al. 1999; Moustgaard et al. 2005; Nielsen et al. 2009; Schook et al. 2005). Pharmacological or experimental manipulation of brain structures has been performed in an attempt to modulate the pigs' learning or 
memory abilities but, compared with the number of rodent studies, relatively few such studies have been performed. There is an urgent need to standardize and (pharmacologically) validate learning and memory tests for pigs.

Information gathered from studies of animal brains influences how we think about species with specific cognitive abilities (Broom and Zanella 2004). These studies also tell us something about the way an animal perceives its environment (Broom and Zanella 2004) and about the complexity of concepts that animals have (Broom 2010). Cognition studies can directly or indirectly contribute to improving animal welfare. For example, it is now known that pigs can recognize their handlers, have preferences, and benefit from environmental enrichment. These aspects should be considered when looking at ways to improve their welfare (Manteuffel et al. 2009). The general public is becoming increasing alert to farm animal welfare, and information and decisions about animal welfare need to be evidence based. Studies of both a fundamental (e.g., pigs capabilities in general) and applied (e.g., the influence of specific treatments on cognitive development) nature are relevant in this context. Although the aims of biomedical and animal welfare scientists are different, behavioral test paradigms are relevant to both fields of research, providing complementary information.

The need for validation and replication of paradigms

This review of the literature on cognitive research in pigs has highlighted deficiencies in both lines of research. More needs to be learned about emotional factors influencing learning in pigs (Lind and Moustgaard 2005), the relation between stress and cognitive function (Mendl 1999), pigs' discriminatory abilities (McLeman et al. 2005), comparison of the cognitive abilities of pigs and other model species, such as mouse, rat, and monkey (Moustgaard et al. 2005), pigs' perception of time (Spinka et al. 1998), memory for objects (Gifford et al. 2007), social and observational learning (Held et al. 2000, 2001a), cognitive abilities related to foraging behavior (Puppe et al. 2007), and cognitive abilities (Ferguson et al. 2009).

While our knowledge of pigs is increasing, there is a need for validated and translational behavioral paradigms (Kornum et al. 2007). The broad variety of experimental findings published in recent years has highlighted the learning abilities of pigs and has indicated which test paradigms might be suitable for this species (e.g. Ferguson et al. 2009; Nielsen et al. 2009). However, the drawback of the great diversity of paradigms used in pig research is that most studies have not (yet) been replicated. Consequently, little is known about the reproducibility and generalizability of results. To date, there is insufficient knowledge to consider pigs as a standard model for biomedical studies of learning and memory. There is always the danger that a number of these studies have yielded idiosyncratic outcomes (van der Staay 2006), and thus it is important to replicate the results of earlier studies, to consolidate the knowledge base (Muma 1993; van der Staay 2006; van der Staay et al. 2009, 2010).

\section{Suitability of specific tasks}

On the basis of this review, we can identify which tests may be appropriate for specific research goals. Some of the tests used to study the cognitive abilities of pigs are suitable for investigating multiple cognitive abilities, while others are only useful for investigating one aspect (as summarized in Table 1). If we also take into account the essential criteria for a behavioral test for pigs mentioned earlier (see Sect. 1.3 of this review), we can consider what type of tests will be most promising for specific research goals (see the overview in Table 2).

Promising advances have been made in the automation, standardization, and complexity of operant tasks for pigs. The tasks designed by Friess et al. (2007) to measure learning after (mild) brain injury seem too simple to detect (subtle) differences, and many tasks would benefit from defining the optimal range of difficulty. The operant minipig tasks used by Ferguson et al. (2009) were relatively complex and automated, but of short duration. If these tasks could be repeated or extended, it might be possible to establish the reasons for their poor performance (e.g., level of cognitive or physical difficulty, motivation, time span). This could then lead to their optimization, e.g. by increasing the level of sensitivity or complexity or by aiming at a more species-specific design, and ultimately to their standardization. Moreover, sorting out the causes of poor performance would also lead to better founded conclusions concerning between-species comparisons (Ferguson's progressive ratio lever-pressing experiment). Operant tasks like those of Moustgaard et al. (2004, 2005) are believed to be relatively complex cognitive tasks that are potentially useful for investigating brain function in pig models of human brain disorders. Repeatedly applying tasks of increasing difficulty or complexity to define the optimal level of difficulty would provide knowledge about the range and limits of the cognitive abilities of pigs, knowledge that could be used to develop standardized tests of brain function in this species. However, what all these operant tests will always lack is the opportunity to tap different relevant natural behaviors of pigs.

Depending on the question to be answered, a spatial task might come closer to fulfilling the criteria listed in the Introduction. Free-choice mazes such as the eight-arm radial maze (Laughlin et al. 1999; Laughlin and Mendl 2000, 2004) and the spatial or foraging arena (Mendl et al. 
Table 2 Overview of cognitive tasks applied in pig research and their opportunities for implementation in the field of animal welfare and biomedical research

\begin{tabular}{|c|c|c|c|c|c|c|c|c|}
\hline $\begin{array}{l}\text { Criteria: } \\
\text { Test } \\
\text { category: }\end{array}$ & $\begin{array}{l}\text { Unimpaired } \\
\text { animals } \\
\text { should be } \\
\text { able to } \\
\text { acquire task }\end{array}$ & $\begin{array}{l}\text { Allow for } \\
\text { detailed } \\
\text { behavioral } \\
\text { analysis }\end{array}$ & $\begin{array}{l}\text { Stress } \\
\text { free }\end{array}$ & $\begin{array}{l}\text { Tap } \\
\text { ecologically } \\
\text { relevant } \\
\text { behaviors }\end{array}$ & Standardization & Automation & $\begin{array}{l}\text { Allow } \\
\text { investigation } \\
\text { of developmental } \\
\text { effects }\end{array}$ & $\begin{array}{l}\text { Complexity } \\
\text { and } \\
\text { sensitivity }\end{array}$ \\
\hline \multicolumn{9}{|l|}{ Classical tasks } \\
\hline Conditioning tasks appetitive & + & - & + & \pm & + & + & - & - \\
\hline $\begin{array}{l}\text { Conditioning tasks aversive } \\
\text { Operant tasks }\end{array}$ & \multicolumn{7}{|c|}{ Operant tasks } & - \\
\hline Lever-pressing tasks & \pm & - & + & - & + & + & - & + \\
\hline $\begin{array}{l}\text { Discrimination tasks (two } \\
\text { choices) }\end{array}$ & + & - & + & - & \pm & \pm & - & \pm \\
\hline $\begin{array}{l}\text { Discrimination tasks } \\
\text { (multiple choices) }\end{array}$ & + & - & + & - & \pm & \pm & - & + \\
\hline Barrier tasks & + & \pm & + & \pm & - & - & \pm & \pm \\
\hline Avoidance tasks & + & - & - & - & + & + & \pm & - \\
\hline Choice tasks & + & - & \pm & - & + & + & \pm & + \\
\hline \multicolumn{9}{|l|}{ Spatial tasks } \\
\hline Water mazes & + & - & - & - & + & \pm & - & - \\
\hline Spatial arena's & + & + & + & \pm & + & + & + & + \\
\hline Multi-access mazes & + & \pm & + & \pm & + & + & + & + \\
\hline Choice tasks & + & \pm & + & + & + & + & - & - \\
\hline \multicolumn{9}{|l|}{ Recognition tasks } \\
\hline ORT & + & + & + & \pm & \pm & - & + & \pm \\
\hline Y-mazes & + & \pm & + & \pm & \pm & - & - & + \\
\hline Social tasks & + & \pm & \pm & + & \pm & - & - & \pm \\
\hline \multicolumn{9}{|l|}{ Awareness tasks } \\
\hline Mirror test & + & \pm & + & + & - & - & + & + \\
\hline
\end{tabular}

Criteria are based on Chap. 1.3 (Implementation of cognitive tasks). + indicates a positive expectancy for this criteria in a particular test category, based on acquired results or analysis of the test construction. \pm indicates that the expectancy might be promising, based on comparable tests applied in other species or analysis of the test construction. - indicates a negative expectancy for this criteria in a particular test category based on acquired results or analysis of the test construction. Due to the multiplicity of tests applied within pig research so far, the categorization made here is a broad outline, and some types of tests are be piled up to keep this table specific and to secure a convenient arrangement

1997; Sneddon et al. 2000) appear to be suitable for studying (spatial) learning as well as memory. Arts et al. (2009) also clearly showed the advantages of the holeboard task for investigating the influence of rearing or housing conditions on cognitive performance. Water mazes (situated somewhere between alley and free-choice mazes) for pigs (Hammell et al. 1975; Siegford et al. 2008) provide measures of both learning and memory. However, this type of 'simple' test has a disadvantage. A water maze for pigs, which are fast growing and large, would have to be adjustable in size to be suitable for testing animals of different age and size. Moreover, while the effect of swimming on the pigs' emotional state is unknown (see Chap. 4.4 ), it is likely that swimming tasks cause stress and therefore such tests are less suitable.
The freedom of movement and choice a pig encounters in free-choice tests such as a spatial arena (Sneddon et al. 2000) might mimic its foraging behavior and make it possible to measure several behavioral domains (e.g., cognitive, sensory, motor domains). Minor adaptations might make these tests suitable for measuring other (cognitive) domains such as discrimination learning (spatial, visual, or olfactory learning of 2 or multiple objects or individuals), problem-solving skills, or motivation. Even observational learning paradigms have been tested in a spatial arena-like apparatus (Held et al. 2000). It is important not to use tasks that are too simple or too difficult, because otherwise study outcomes might be false positive or negative (like the outcomes in Hagl et al.' 'first problem' (see Hagl et al. 2005)). 
Y-mazes have proven effective for studying mainly social discrimination or recognition learning (Koba and Tanida 1999; Kristensen et al. 2001; McLeman et al. 2005; Tanida and Nagano 1998). These tests, which make use of a relatively simple apparatus, should be used more often to study the sensory capacities of pigs, about which our knowledge is relatively limited at the moment. McLeman et al. (2008) also showed that the Y-maze can be adapted to a more automated and controllable apparatus in which auditory, olfactory, and visual capacities can be tested in combination or separately. In contrast, the ORT test has proven relevance in rodents but not in pigs. In theory, this test could be promising and potentially fulfils several of the criteria mentioned in Table 2. The main question to be solved here is whether pigs show a preference for investigating an unfamiliar object when it is presented together with a familiar one.

The latest development in cognitive pig research is related to the study of 'animal consciousnesses'. To our knowledge, only one study has investigated this. Broom et al. (2009) applied a test with a mirror (not to be confused with the self-awareness Mirror Test of Gallup 1970) to assess awareness in pigs. The outcomes of this study support the notion that pigs are able to obtain and use information from an object (mirror), and thus this mirror task may prove a valuable task to assess the higher cognitive abilities of pigs.

In conclusion, when looking at the criteria outlined for cognitive tests for pigs to obtain the preferred level of reliability and validity, simple tasks such as the Y-maze could be appropriate for some purposes, but free-choice tasks, and especially spatial free-choice tasks, are the most promising tests. These tasks can be stress-free provided that animals receive a long-enough habituation period. Automation is possible, complexity can be increased or decreased, and animals are able to show a wide range of species-relevant behaviors.

\section{Cognitive research in pigs: prerequisites}

\section{Stress and cognitive functioning}

Performing under stress or arousal is known to influence or even impair memory (Schwabe and Wolf 2010) and to disrupt cognitive processes (Mendl 1999), although the effect seems to be task specific. Performance on appetitively motivated spatial tasks, such as the holeboard task, may be negatively influenced by chronic stress. Studies with rodents suggest that chronic stress impairs memory performance in spatial tasks such as the holeboard or radial-arm maze, whereas learning in spatial tasks that evoke moderate to high levels of arousal (e.g., water mazes) seems to be unaffected or is even facilitated by chronic stress (see review of Conrad 2010). Several studies have used electrical shocks as stimulus in aversive learning tasks. The animal's response to the CS is believed to be motivated by aversion of the shock caused by pain and/or fear. Since pain and fear are associated with stress, the use of this type of reinforcer is not recommended when studying learning and memory in pigs, except in the case of studies designed to assess learning during stressful circumstances. As stress might adversely affect results, caution is warranted if it is not known whether a certain procedure or reinforcer evokes stress. The pigs in the experiment of Spinka et al. (1998) were free to choose for short or long confinement during testing, but despite the presence of food reward, confinement still is a negative reinforcer. Thus, there is a probability that stress occurs due to negative reinforcement.

This is also true for water mazes. Although little is known about whether pigs find swimming pleasant or unpleasant, they are able to swim (Albarella et al. 2007; Bennett 1970). However, they probably do not swim often, and therefore swimming might not be the best behavior to choose for using in learning and memory tasks. Using conspecifics as reinforcing stimuli could cause stress in piglets if they are removed from the sow and their littermates. This is what Siegford et al. (2008) did in their study. In this specific case, stress might not only have influenced learning performance, but might also have interfered with the original research question (does early cognitive performance reduce stress during weaning) because it is uncertain whether weaning stress was reduced because of the piglets' prior cognitive experience or their prior exposure to (a) stressful situation(s).

Even less is known about the influence of positive arousal (e.g., anticipation of reward) on learning and memory performance in animals. Positive arousal has been found to influence performance in humans, and probably also does so in pigs and other animals. A positive mood state can enhance cognition in humans (Ashby et al. 1999), and the mood state at the time of information retrieval influences performance. Emotional information is remembered better when mood at the time of retrieval matches the information to be retrieved (positive mood, positive material; (Lewis et al. 2005) Thus, it would be preferable to prevent negative as well as positive stress and arousal before and during testing as much as possible.

\section{Versatility of tasks}

Carefully designed reliable equipment that can be used in several tasks would provide a good basis for gathering basic, factual, and replicable results. The larger size of pigs means that test equipment will be more expensive than for rodents, and for this reason it should be appropriate for 
testing multiple variables and hypotheses. The apparatus should be designed in such a way that animals of different ages, breeds, sizes, and sex can be tested without evoking stress (Siswanto et al. 2008) and should be based on the pig's natural abilities.

\section{Translatability of results}

The translatability of findings from pigs to humans and other species is an important consideration when developing behavioral cognitive tests suitable for pigs. The physiology of pigs resembles that of humans, which enhances the translatability of data to humans. A paradigm that can be used for animals and humans alike is expected to promote translational value. Technological advances have led to the development of virtual versions of animal-based tasks for use in human research, and spatial tasks in particular have made comparisons and translatability between animal and human studies easier. Examples of virtual reality spatial tasks for which analogs have been designed for humans and other animal species are the cognitive holeboard (Cánovas et al. 2008), the Morris Water Maze (Astur et al. 2002; Bartsch et al. 2010) and various spatial mazes (Grön et al. 2000; Kahana et al. 1999). Because genetically highly homogenous animals are used in most studies with rodents as subjects, whereas humans are highly heterogeneous, Hoyte et al. (2004) suggested that interventions should have demonstrated effectiveness in 2 species, in order to improve the translatability of findings. Pigs could be one of the species tested.

\section{Factual knowledge about the species}

A large amount of research has been performed on learning and memory in pigs. In particular, pig models are expected to have a higher translational value than commonly used rodent models. There are, however, a number of gaps in our knowledge about pigs that need to be closed. For example, little is known about the sensory capacities of pigs in general. Furthermore, there is a lack of replicated experimental findings and a lack of studies trying to optimize experimental approaches with pigs as subjects. Yet reliable equipment and validated test systems are needed to enable biomedical researchers and welfare specialists to study all aspects of learning and memory in this species. Such knowledge is a prerequisite for developing and validating pig models and for translating findings to management systems that improve pig welfare under production conditions.

\section{Conclusion}

This article has reviewed behavioral test paradigms that may contribute to biomedical research and pig welfare; however, systematic research is lacking. A critical point when designing tasks is that they should reflect the range of natural abilities of a species. To this end, further research into the sensory and motor abilities of pigs is urgently needed.

Several types of tests have proven useful. Simple twochoice mazes (mainly Y-mazes) are suited to investigate social discrimination and recognition, and sensory capacities. Operant (lever-pressing like) tests meet several of the criteria that tasks for testing cognition in pigs should fulfill. In particular, they can easily be automated and standardized. Free-choice spatial tests seem to be especially promising. In contrast to operant tasks, they are able to measure several behavioral domains simultaneously, and various paradigms have successfully been developed. While these tests appear to be promising instruments to evaluate the cognitive abilities of pigs, validation studies are still lacking. The growing interest in pig models for cognitive research and the need to improve animal welfare might provide the impetus needed to lift cognitive pig research to a higher level.

Open Access This article is distributed under the terms of the Creative Commons Attribution Noncommercial License which permits any noncommercial use, distribution, and reproduction in any medium, provided the original author(s) and source are credited.

\section{References}

Albarella U, Dobney K, Ervynck K, Rowley-Conwy P (2007) Pigs and humans: 10.000 years of interactions. Oxford University Press, Oxford

Arndt SS, Laarakker MC, van Lith HA, van der Staay FJ, Gieling E, Salomons AR, van't Klooster J, Ohl F (2009) Individual housing of mice-impact on behaviour and stress responses. Physiol Behav 97:385-393

Arnfred SM, Lind NM, Hansen AK, Hemmingsen RP (2004) Prepulse inhibition of the acoustic startle eye-blink in the Göttingen minipig. Behav Brain Res 151:295-301

Arts JWM, van der Staay FJ, Ekkel ED (2009) Working and reference memory of pigs in the spatial holeboard discrimination task. Behav Brain Res 205:303-306

Ashby FG, Isen AM, Turken AU (1999) A neuropsychological theory of positive affect and its influence on cognition. Psychol Rev 106(3):529-550

Astur RS, Taylor LB, Mamelak AN, Philpott L, Sutherland RJ (2002) Humans with hippocampus damage display severe spatial memory impairments in a virtual Morris water task. Behav Brain Res 132:77-84

Baldwin BA (1969) The study of behaviour in pigs. Br Vet J 125:281

Baldwin BA (1979) Operant studies on the behaviour of pigs and sheep in relation to the physical environment. J Anim Sci 49

Baldwin BA, Meese GB (1977) Sensory reinforcement and illumination preference in the domesticated pig. Anim Behav 25:497-507

Baldwin BA, Meese GB (1979) Social behaviour in pigs studied by means of operant conditioning. Anim Behav 27:947-957

Baldwin BA, Stephens DB (1973) The effects of conditioned behaviour and environmental factors on plasma corticosteroid levels in pigs. Physiol Behav 10:267-274 
Barnes RH, Moore U, Pond WG (1969) Behavioural abnormalities in young adult pigs caused by malnutrition in early life. J Nutrition 100:149-155

Bartsch T, Schönfeld R, Müller FJ, Alfke K, Leplow B, Aldenhoff J, Deuschl G, Koch JM (2010) Focal lesions of human hippocampal CA1 neurons in transient global amnesia impair place memory. Science 328:1412

Bauer R, Brust P, Walter B, Vorwieger G, Bergmann R, Elhalag E, Fritz A, Steinbach J, Füchtner F, Hinz R, Zwiener U, Johannsen B (2002) Effect of hypoxia/hypercapnia on metabolism of 6-[F]fluoro-L-DOPA in newborn piglets. Brain Res 934:23-33

Bennett MK (1970) Aspects of the Pig. Agric Hist 44:223-236

Boissy A, Manteuffel G, Jensen MB, Moe RO, Spruijt B, Keeling LJ, Winckler C, Forkma B, Dimitrov I, Langbein J, Bakken M, Veissier I, Aubert A (2007) Assessment of positive emotion in animals to improve their welfare. Physiol Behav 92:375-397

Bolhuis JE, Schouten WGP, Leeuw de JA, Schrama JW, Wiegant VM (2004) Individual coping characteristics, rearing conditions and behavioural flexibility in pigs. Behav Brain Res 152:351-360

Bouger PC, van der Staay FJ (2005) Rats with scopolamine- or MK801-induced spatial discrimination deficits in the cone field task: animal models for impaired spatial orientation performance. Neuropsychopharmacology 15:331-346

Breland K, Breland M (1915) A field of applied animal psychology. Am Psychol 6:202-204

Broom DM (2010) Cognitive ability and awareness in domestic animals and decisions about obligations to animals. Appl Anim Behav Sci 126:1-11

Broom DM, Zanella AJ (2004) Brain measures which tell us about animal welfare. Anim Welf 13:41-45

Broom DM, Sena H, Moynihan KL (2009) Pigs learn what a mirror image represents and use it to obtain information. Anim Behav 78:1037-1041

Cánovas R, Espínola M, Iribarne L, Cimadevilla JM (2008) A new virtual task to evaluate human place learning. Behav Brain Res 190:112-118

Chaput RL, Barron EL, Marrenfeltz JK, Dalton TK, Wolfe WW (1973) The miniature pig: a biomedical model for behavioural studies. Lab Anim Sci 23:711-715

Chen K, Baxter T, Muir WM, Groenen MA, Schook LB (2007) Genetic resources, genome mapping and evolutionary genomics of the pig (Sus scrofa). Int J Biol Sci 3:153-165

Choleris E, Kavaliers M (1999) Social learning in animals: sex differences and neurobiological analysis. Pharmacol Biochem Behav 64:767-776

Conrad CD (2010) A critical review of chronic stress effects on spatial learning and memory. Prog Neuro-Psychopharmacol Biol Psychiatry 34:742-755

Crannell CW (1942) The choice point behavior of rats in a multiple path elimination problem. J Psychol 13:201-222

Croney CC, Adams KM, WashingtonCG Stricklin WR (2003) A note on visual, olfactory and spatial cue use in foraging behaviour of pigs: indirectly assessing cognitive abilities. Appl Anim Behav Sci 83:303-308

Curtis SE, Stricklin WR (1991) The importance of animal cognition in agricultural animal production systems: an overview. J Anim Sci 69:2001-2007

Danielsen EH, Smith DF, Andersen F, Gee AD, Bender D, Hansen SB, Hermansen F, Østergaard L, Cumming P, Gjedde A (2001) FDOPA metabolism in the adult porcine brain: influence of tracer circulation time and VOI selection on estimates of striatal DOPA decarboxylation. J Neurosci Methods 111:157-168

de Groot J, Boersma W, van der Staay FJ, Niewold T, Stockhofe N, Koopmans SJ, van der Lende T, Schuurman T (2005) Development of domestic animal models for the study of the ontogeny of human disease. In: Coe DHC (ed) Perinatal programming: early life determinants of adult health $\&$ disease. Taylor \& Francis, London, pp 117-128

de Jong IC, Prelle IT, Van d Burgwal JA, Lambooij E, Korte SM, Blokhuis HJ, Koolhaas JM (2000) Effects of environmental enrichment on behavioural responses to novelty, learning, and memory, and the circadian rhythm in cortisol in growing pigs. Physiol Behav 68:571-578

de Souza AS (2006) Social recognition in neonatal pigs and the effects of acute stressors on it. Dissertation, Michigan State University

de Souza AS, Jansen J, Tempelman RJ, Mendl M, Zanella AJ (2006) A novel method for testing social recognition in young pigs and the modulating effects of relocation. Appl Anim Behav Sci 99:77-87

Duncan IJ, Petherick JC (1991) The implications of cognitive processes for animal welfare. J Anim Sci 69:5017-5022

Ennaceur A, Delacour J (1988) A new one-trial test for neurobiological studies of memory in rats I: Behavioral data. Behav Brain Res 31:47-59

Ennaceur A, Meliani K (1992) A new one-trial test for neurobiological studies of memory in rats III spatial vs non-spatial working memory. Behav Brain Res 51:83-92

Ennaceur AAC, Costa JC, Delacour J (1989) A new one-trial test for neurobiological studies of memory in rats II: effects of piracetam and pramiracetam. Behav Brain Res 33:197-207

Entsu S, Dohi H, Yamada A (1992) Visual acuity of cattle determined by the method of discrimination learning. Appl Anim Behav Sci 34:1-10

Fang M, Li J, Rudd JA, Wai SM, Yew JCC, Yew DT (2006) fMRI Mapping of cortical centers following visual stimulation in postnatal pigs of different ages. Life Sci 78

Ferguson SA, Gopee NV, Paule MG, Howard PC (2009) Female Mini-pig performance of temporal response differentation, incremental repeated aquisition, progressive ration operant tasks. Behav Processes 80(1):28-34

Fraser D, Thompson BK (1991) Armed sibling rivalry among suckling piglets. Behav Ecol Sociobiol 29:9-15

Friess SH, Ichord RN, Owens K, Ralston J, Rizol R, Overall KL, Smith C, Helfaer MA, Margulies SS (2007) Neurobehavioural functional deficits following closed head injury in the neonatal pig. Exp Neurol 204:234-243

Gallup GG (1970) Chimpanzees: Self-Recognition. Science $167: 86-87$

Gifford AK (2005) Assessing object recognition memory in the domestic pig. MSc thesis, Washington State University

Gifford AK, Cloutier S, Newberry RC (2007) Objects as enrichment: effect of object exposure time and delay interval on object recognition memory of the domestic pig. Appl Anim Behav Sci 107:206-217

Glaser D, Wanner M, Tinti JM, Nofre C (2000) Gustatory responses of pigs to various natural and artificial compounds known to be sweet in man. Food Chem 68:375-385

Graf R (1976) Das visuelle Orientierungsvermögen der Schweine in Abhängigkeit von der Beleuchtungsstärke. In: Instituut voor Veeteeltkundig Onderzoek, Zeist, pp 56

Graves HB (1984) Behaviour and ecology of wild and feral swine (Sus Scrofa). J Anim Sci 58:482-492

Grön G, Wunderlich AP, Spitzer M, Tomczak R, Riepe MW (2000) Brain activation during human navigation: gender-different neural networks as substrate of performance. Nature Neurosci 3:404-408

Gustafsson M, Jensen P, de Jonge FH, Schuurman T (1999) Domestication effects on foraging strategies in pigs (Sus scrofa). Appl Anim Behav Sci 62:305-317

Hagl C, Weisz DJ, Khaladj N, Griepp MM, Spielvogel D, Yang B, de Asla RA, Bodian CA, Griepp RB (2005) Use of a maze to detect 
cognitive dysfunction in a porcine model of hypothermic circulatory arrest. Ann Thorac Surg 79:1307-1315

Hammell DL, Kratzer DD, Bramble WJ (1975) Avoidance and maze learning in pigs. J Anim Sci 40:573-579

Heffner HE, Heffner AS (1992) Auditory perception in farm animals and the environment. In: Phillips C, Piggins D (eds) CAB International, Wallingford, pp 159-184

Held S, Mendl M, Devereux C, Byrne RW (2000) Social tactics of pigs in a competitive foraging task: the 'informed forager' paradigm. Anim Behav 59:569-576

Held S, Mendl M, Devereux C, Byrne RW (2001a) Behaviour of domestic pigs in a visual perspective task. Behaviour 138:13371354

Held S, Mendl M, Devereux C, Byrne RW (2001b) Studies in social cognition: from primates to pigs. Anim Welf 10:209-217

Held S, Mendl M, Laughlin K, Byrne RW (2002) Cognition studies with pigs: livestock cognition and its implication for production. J Anim Sci 80:E10-E17

Held S, Baumgartner J, Kilbride A, Byrne RW, Mendl F (2005) Foraging behaviour in domestic pigs (Sus scrofa): remembering and prioritizing food sites of different value. Anim Cogn 8:114-121

Held S, Cooper JJ, Mendl MT (2009) Advances in the study of cognition, behavioural priorities and emotions. In: MarchantForde JN (ed) The welfare of pigs. anim welf, vol 7. Springer, Heidelberg, pp 47-94

Hemmer H (1990) Domestication-the decline of environmental appreciation. Cambridge University Press, Cambridge

Hemsworth PH, Verge J, Coleman GJ (1996) Conditioned approachavoidance responses to humans: the ability of pigs to associate feeding and aversive social experiences in the presence of humans with humans. Appl Anim Behav Sci 50:71-82

Hofman MA (1985) Size and shape of the cerebral cortex in mammals (Part 1 of 2) I. The cortical surface. Brain Behav Evol 27:28-34

Hoyte L, Kaur J, Buchan AM (2004) Lost in translation: taking neuroprotection from animal models to clinical trials. Exp Neurol 188:200-204

Jensen P (2003) The ethology of domestic animals. An introductory text, CAB International, Wallingford

Kahana MJ, Sekuler R, Caplan JB, Kirschen M, Madsen JR (1999) Human theta oscillations exhibit task dependence during virtual maze navigation. Nature 399:781-784

Kennedy JM, Baldwin BA (1972) Taste preference in pigs for nutritive and non-nutritive sweet solutions. Anim Behav 20:706718

Kirsch I, Lynn SJ, Vigorito M, Miller RR (2004) The role of cognition in classical and operant conditioning. J Clin Psychol 60:369-392

Koba Y, Tanida H (1999) How do miniature pigs discriminate between people? The effect of exchanging cues between a nonhandler and their familiar handler on discrimination. Appl Anim Behav Sci 61:239-252

Köhn F, Sharifi AR, Simianer H (2007) Modeling of the growth of the Göttingen minipig. J Anim Sci 85:84-92

Koolhaas JM, de Boer de SF, Buwalda B (2006) Stress and adaptation-toward ecologically relevant animal models. Curr Dir Psychol Sci 15:109-112

Kornum BR, Thygesen KS, Nielsen TR, Knudsen GM, Lind NM (2007) The effect of the inter-phase delay interval in the spontaneous object recognition test for pigs. Behav Brain Res 181:210-217

Kratzer DD (1969) Effects of age on avoidance learning in pigs. J Anim Sci 28:175-179

Kratzer DD (1971) Learning in farm animals. J Anim Sci 32:1268-1273

Kristensen HH, Jones RB, Schofield CP, White RP, Wathes CM (2001) The use of olfactory and other cues for social recognition by juvenile pigs. Appl Anim Behav Sci 72:321-333
Lachman SJ, Brown CR (1957) Behavior in a free choice multiple path elimination problem. J Psychol 43:27-40

Larsen MO, Rolin B (2004) Use of the Göttingen minipig as a model of diabetes, with special focus on type 1 diabetes research. ILAR $\mathrm{J} 45$

Laughlin K, Mendl M (2000) Pigs shift too: foraging strategies and spatial memory in the domestic pig. Anim Behav 60:403-410

Laughlin K, Mendl M (2004) Costs of acquiring and forgetting information affect spatial memory and its susceptibility to interference. Anim Behav 68:97-103

Laughlin K, Huck M, Mendl M (1999) Disturbance effects of environmental stimuli on pig spatial memory. Appl Anim Behav Sci 64:169-180

Lewis PA, Critchley HD, Smith AP, Dolan RJ (2005) Brain mechanisms for mood congruent memory facilitation. NeuroImage 25:1214-1223

Lien J, Klopfer FD (1978) Some relations between stereotyped suckling in piglets and exploratory behaviour and discrimination reversal learning in adult swine. Appl Anim Ethol 4:223-233

Lind NM, Moustgaard A (2005) Response to novelty correlates with learning rate in a go/no-go task in Göttingen Minipigs. Neural Plast 12

Lind NM, Arnfred SM, Hemmingsen RP, Hansen AK (2004) Prepulse inhibition of the acoustic startle reflex in pigs and its disruption by D-amphetamine. Behav Brain Res 155:217-222

Lind NM, Moustgaard A, Jelsing J, Vajta G, Cumming P, Hansen AK (2007) The use of pigs in neuroscience: modelling brain disorders. Neurosci Biobehav Rev 31:728-751

Lunney JK (2007) Advances in swine biomedical model genomics. Int J Biol Sci 3:179-184

Macellini S, Ferrari PF, Bonini L, Fogassi L, Paukner A (2010) A modified mark test for own-body recognition in pig-tailed macaques (Macaca nemestrina). Anim Cogn 13(4):631-639

Manteuffel G, Langbein J, Puppe B (2009) Increasing farm animal welfare by positively motivated instrumental behaviour. Appl Anim Behav Sci 118:191-198

Markou A, Chiamulera C, Geyer MA, Tricklebank M, Steckler T (2009) Removing obstacles in neuroscience drug discovery: The future path for animal models. Neuropsychopharmacology 34:74-89

Mauget R (1984) Rythme d'activité et budget-temps chez le sanglier européen (Sus scrofa L.). In: Spitz F, Pépin D (eds) Symposium International sur le Sanglier. INRA, Toulouse, pp 79-92

McLeman MA, Mendl M, Jones RB, White R, Wathes CM (2005) Discrimination of conspecifics by juvenile domestic pigs, sus scrofa. Anim Behav 70:451-461

McLeman MA, Mendl MT, Jones RB, Wathes CM (2008) Social discrimination of familiar conspecifics by juvenile pigs, Sus scrofa: development of a non-invasive method to study the transmission of unimodal and bimodal cues between live stimuli. Appl Anim Behav Sci 115:123-137

Meehan CL, Mench JA (2007) The challenge of challenge: can problem solving opportunities enhance animal welfare? Appl Anim Behav Sci 102:246-261

Meese GB, Conner DJ, Baldwin BA (1975) Ability of the pig to distinguish between conspecific urine samples using olfaction. Physiol Behav 15:121-125

Mendl M (1999) Performing under pressure: stress and cognitive function. Appl Anim Behav Sci 65:221-244

Mendl M, Paul ES (2004) Consciousness, emotion and animal welfare: insights from cognitve science. Anim Welf 13:S17

Mendl M, Laughlin K, Hitchcock D (1997) Pigs in space: spatial memory and its susceptibility to interference. Anim Behav 54:1491-1508

Mendl M, Randle K, Pope S (2002) Young female pigs can discriminate individual differences in odours from conspecific urine. Anim Behav 64:97-101 
Mendl M, Burman OHP, Parker RMA, Paul ES (2009) Cognitive bias as an indicator of animal emotion and welfare: emerging evidence and underlying mechanisms. Appl Anim Behav Sci 118:161-181

Mikkelsen M, Moller A, Jensen LH, Pedersen A, Harajehi JB, Pakkenberg H (1999) MPTP-Induced parkinsonism in Minipigs: a behavioural, biochemical, and histological study. Neurotoxicol Teratol 21:169-175

Moore AU, Marcuse FL (1945) Salivary, cardiac and motor indices of conditioning in two sows. J Comp Psychol 38:1-16

Morris R (1984) Developments of a water-maze procedure for studying spatial learning in the rat. J Neurosci Methods 11:47

Moustgaard A, Lind NM, Hemmingsen R, Hansen AK (2002) Spontaneous object recognition in the Göttingen Minipig. Neural Plast 9(4):255-259

Moustgaard A, Arnfred SM, Lind NM, Hansen AK, Hemmingsen R (2004) Discriminations, reversals, and extra-dimensional shifts in the Göttingen minipig. Behav Processes 67:27-37

Moustgaard A, Arnfred SM, Lind NM, Hemmingsen R, Hansen AK (2005) Acquisition of visually guided conditional associative tasks in Göttingen minipigs. Behav Processes 68:97-102

Muma JR (1993) The need for replication. J Speech Hear Res 36:927-930

Nielsen TR, Kornum BR, Moustgaard A, Gade A, Lind NM, Knudsen GM (2009) A novel spatial delayed non-match to sample (DNMS) task in the Göttingen Minipig. Behav Brain Res 196:93-98

Noble M, Adams CK (1963) Conditioning in pigs as a function of the interval between CS and US. J Comp Physiol Psychol 56:215219

Nofre C, Glaser D, J- Tinti, Wanner M (2002) Gustatory responses of pigs to sixty compounds tasting sweet to humans. J Anim Physiol Anim Nutr 86:90-96

Nunoya T, Shibuya K, Saitoh T, Yazawa H, Nakamura K, Yasuko Baba Y, Hirai T (2007) Use of miniature pig for biomedical research, with reference to toxicologic studies. JTP 20:125-132

Ohl F, Arndt SS, van der Staay FJ (2008) Pathological anxiety in animals. Vet J 175:18-26

Olton DS, Samuelson RJ (1976) Remembrance of places passed: spatial memory in rats. J Exp Psychol 2:97-116

Pacioni G (1986) Truffle hunting in Italy. Bull Br Mycol Soc 20:50-51

Paul ES, Harding EJ, Mendl M (2005) Measuring emotional processes in animal: the utility of a cognitive approach. Neurosci Bio Beh Rev 29:469-491

Petersen B, Carnwath JW, Niemann H (2008) The perspectives for porcine-to-human xenografts. Comp Immunol Microbiol Infect Dis 32:91-105

Puppe B, Ernst K, Schön PC, Manteuffel G (2007) Cognitive enrichment affects behavioural reactivity in domestic pigs. Appl Anim Behav Sci 105:75-86

Rehfeldt C, Kuhn G (2006) Consequences of birth weight for postnatal growth performance and carcass quality in pigs as related to myogenesis. J Anim Sci 84:E113

Rescorla RA (1988) Behavioral studies of pavlovian conditioning. Ann Rev Neurosci 11:329-352

Sachs DH (1994) The pig as a potential xenograft donor. Vet Immunol Immunopathol 43:185-191

Schook L, Beattie C, Beever J, Donovan S, Jamison R, Zuckermann F, Niemi S, Rothschild M, Rutherford M, Smith D (2005) Swine in biomedical research: creating the building blocks of animal models. Anim Biotechnol 16:183-190

Schwabe L, Wolf OT (2010) Learning under stress impairs memory formation. Neurobiol Learn Mem 93:183-188
Siegford JM, Rucker G, Zanella AJ (2008) Effects of pre-weaning exposure to a maze on stress responses in pigs at weaning and on subsequent performance in spatial and fear-related tests. Appl Anim Behav Sci 110:189-202

Sik A, van Nieuwehuyzen P, Prickaerts J, Blokland A (2003) Performance of different mouse strains in an object recognition task. Behav Brain Res 14:49-54

Siswanto H, Hau J, Carlsson H, Goldkuhl R, Abelson KSP (2008) Corticosterone concentrations in blood and excretion in faeces after ACTH administration in male Sprague-Dawley rats. In Vivo 22:435-440

Sneddon IA, Beattie VE, Dunne L, Neil W (2000) The effect of environmental enrichment on learning in pigs. Anim Welf 9:373-383

Spinka M, Duncan IJH, Widowski TM (1998) Do domestic pigs prefer short-term to medium-term confinement? Appl Anim Behav Sci 58:221-232

Tanida H, Nagano Y (1998) The ability of miniature pigs to discriminate between a stranger and their familiar handler. Appl Anim Behav Sci 56:149-159

Tanida H, Senda K, Suzuki S, Tanaka T, Yoshimoto T (1991) Colour discrimination in weanling pigs. Anim Sci Technol 62:10291034

Thor DH, Holloway WR (1982) Social memory of the male laboratory rat. J Comp Physiol Psychol 69:1000-1006

Toates F (2004) Cognition, motivation, emotion and action: a dynamic and vulnerable interdependence. Appl Anim Behav Sci 86:173-204

van der Staay FJ (2002) Assessment of age-associated cognitive deficits in rats: a tricky business. Neurosci Biobehav Rev 26:753-759

van der Staay FJ (2006) Animal models of behavioral dysfunctions: basic concepts and classifications, and an evaluation strategy. Brain Res Rev 52(1):131-159

van der Staay FJ, Arndt SS, Nordquist RE (2009) Evaluation of animal models of neurobehavioral disorders. Behav Brain Funct 5:11

van der Staay FJ, Arndt SS, Nordquist RE (2010) The standardization-generalization dilemma: a way out. Genes Brain Behav 9:849-855

van Rooijen J (1982) Operant preference tests with pigs. Appl Anim Ethol 9:87-88

Vodička P, Smetana K, Dvořánková B, Emerick T, Xu YZ, Ourednik J, Ourednik V, Motlík J (2005) The miniature pig as an animal model in biomedical research. Ann N Y Acad Sci 1049:161-171

Wainwright PE, Colombo J (2006) Nutrition and the development of cognitive functions: interpretation of behavioural studies in animals and human infants. Am J Clin Nutr 84:961-970

Wang B, Yu B, Karim M, Hu H, Sun Y, McGreevy P, Petocz P, Held S, Brand-Miller J (2007) Dietary sialic acid supplementation improves learning and memory in piglets. Am J Clin Nutr 85:561-569

Wechsler B, Lea SEG (2007) Adaptation by learning: Its significance for farm animal husbandry. Appl Anim Behav Sci 108:197-214

Yerkes RM, Coburn CA (1915) A study of the behaviour of the pig sus crofa by the multiple choice method. J Anim Behav 5:185-188, 188a, 189-225

Zhang J, Groff RF, Chen X, Browne KD, Huang J, Schwartz ED, Meaney DF, Johnson VE, Stein SC, Rojkjaer R, Smith DH (2008) Hemostatic and neuroprotective effects of human recombinant activated factor VII therapy after traumatic brain injury in pigs. Exp Neurol 210:645-655

Zonderland JJ, Cornelissen L, Wolthuis-Fillerup M, Spoolder HAM (2008) Visual acuity of pigs at different light intensities. Appl Anim Behav 111:28-37 